\title{
Nitrodiaziridines: Unattainable Yet, but Desired
}

\section{Energetic Materials}

Dmitry V. Khakimov*a,b, Leonid L. Fershtat ${ }^{a}$, Tatyana S. Pivina ${ }^{a}$, Nina N. Makhova ${ }^{a}$

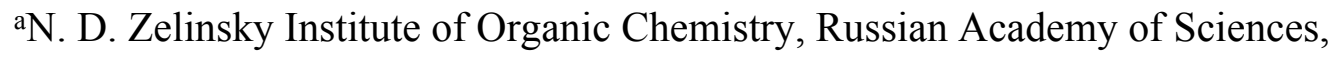

47 Leninsky prosp., Moscow 119991, Russian Federation

'Federal State Unitary Enterprise "Keldysh Research Center",

Onezhskaya Str., 8, Moscow 125438, Russian Federation

Nitrodiaziridines_cis_unmodified_coords (cif format):

1-nitrodiaziridine (cis-form)

data $-1.70433 \mathrm{E}+01$

_chemical_name_systematic

;RAS DNDAZ_1_cis PVDZ

$E($ total $)=-1.70433 \mathrm{E}+01 \mathrm{E}(\mathrm{coul})=-7.35432 \mathrm{E}+00 \mathrm{E}(\mathrm{vdW})=-9.68895 \mathrm{E}+00$ Density $=1.60146$

;

_cell_length_a 8.941

_cell_length_b 8.941

_cell_length_c 18.486

_cell_angle_alpha 90.00

_cell_angle_beta 90.00

_cell_angle_gamma 90.00

_cell_formula_units_Z 16

_symmetry_space_group_name_H-M 'I 41/A ' 
_symmetry_Int_Tables_number 88

loop_

_symmetry_equiv_pos_as_xyz

$1 \mathrm{x}, \mathrm{y}, \mathrm{z}$

2 3/4-y, $1 / 4+x, 1 / 4+z$

3 1/2-x,-y, $1 / 2+z$

4 3/4+y,3/4-x,3/4+z

$5-\mathrm{x},-\mathrm{y},-\mathrm{z}$

$61 / 4+y, 3 / 4-x, 3 / 4-z$

$71 / 2+x, y, 1 / 2-z$

8 1/4-y, 1/4+x, 1/4-z

$91 / 2+x, 1 / 2+y, 1 / 2+z$

$101 / 4-y, 3 / 4+x, 3 / 4+z$

$11-\mathrm{x}, 1 / 2-\mathrm{y}, \mathrm{z}$

12 1/4+y, 1/4-x,1/4+z

$131 / 2-x, 1 / 2-y, 1 / 2-z$

14 3/4+y,1/4-x,1/4-z

$15 \mathrm{x}, 1 / 2+\mathrm{y},-\mathrm{z}$

16 3/4-y,3/4+x,3/4-z

loop

_atom_site_label

_atom_site_fract_X

_atom_site_fract_y

_atom_site_fract_z

C1 $\quad-0.19138 \quad 0.38421 \quad 0.49103$

\# 1

N2 $\quad-0.21068 \quad 0.52488 \quad 0.45025$

\# 2

N3 $\quad-0.11019 \quad 0.40792 \quad 0.42433$

\# 3

$\begin{array}{llll}\text { N'4 } & -0.36202 & 0.51851 & 0.41399\end{array}$

\# 4

$\begin{array}{llll}\text { O5 } & -0.37828 & 0.43378 & 0.36281\end{array}$

\# 5

$\begin{array}{llll}\text { O6 } & -0.45079 & 0.60673 & 0.43858\end{array}$

\#6

H7 $\quad-0.28628 \quad 0.30702 \quad 0.49099$

\# 7

H8 $\quad-0.12856 \quad 0.39419 \quad 0.54141$

\# 8

$\begin{array}{llll}H^{* 9} & -0.16295 & 0.35251 & 0.38279\end{array}$

\# 9

$\begin{array}{llll}\text { \#XC1 } & -0.18609 & 0.41341 & 0.47417\end{array}$

\# 10

$\begin{array}{llll}\text { \#XN2 } & -0.18469 & 0.56842 & 0.45429\end{array}$

\# 11 


$\begin{array}{lcccc}\text { \#XN3 } & -0.03637 & 0.42907 & 0.42598 & \# 12 \\ \text { \#XN'4 } & -0.34165 & 0.54646 & 0.41725 & \# 13 \\ \text { \#XO5 } & -0.39343 & 0.45956 & 0.37715 & \# 14 \\ \text { \#XO6 } & -0.38953 & 0.58397 & 0.44096 & \# 15 \\ \text { \#XH7 } & -0.34796 & 0.24571 & 0.50039 & \# 16 \\ \text { \#XH8 } & -0.09394 & 0.40162 & 0.56511 & \# 17 \\ \text { \#XH*9 } & -0.14486 & 0.33282 & 0.37134 & \# 18 \\ \text { \#XLP2+ } & -0.15760 & 0.53819 & 0.43565 & \# 19 \\ \text { \#XLP2- } & -0.21720 & 0.50804 & 0.43115 & \# 20 \\ \text { \#XLP3+ } & -0.08948 & 0.41139 & 0.43268 & \# 21 \\ \text { \#XLP3- } & -0.10671 & 0.47047 & 0.45601 & \# 22 \\ \text { \#XLP4+ } & -0.34385 & 0.55591 & 0.41299 & \# 23 \\ \text { \#XLP4- } & -0.35001 & 0.53693 & 0.42548 & \# 24 \\ \text { \#XLP5+ } & -0.40223 & 0.47928 & 0.41332 & \# 25 \\ \text { \#XLP5- } & -0.36321 & 0.51194 & 0.42444 & \# 26 \\ \text { \#XLP6+ } & -0.43872 & 0.53739 & 0.39358 & \# 27 \\ \text { \#XLP6- } & -0.48621 & 0.56766 & 0.40590 & \# 28 \\ \text { \#END } & & & & \end{array}$

\section{3-nitrodiaziridine (cis-form)}

data_00199_-2.10897E+01

_chemical_name_systematic

;RAS DNDAZ_1i_cis1 PVDZ

$\mathrm{E}($ total $)=-2.10897 \mathrm{E}+01 \mathrm{E}(\mathrm{coul})=-9.47178 \mathrm{E}+00 \mathrm{E}(\mathrm{vdW})=-1.16180 \mathrm{E}+01$ Density $=1.82903$

;

_cell_length_a 7.167

_cell_length_b 5.304

_cell_length_c 9.081

_cell_angle_alpha 90.00

_cell_angle_beta 110.46

_cell_angle_gamma 90.00

_cell_formula_units_Z 4

_symmetry_space_group_name_H-M 'P 21/C '

_symmetry_Int_Tables_number 14 
loop_

_symmetry_equiv_pos_as_xyz

$1 \mathrm{x}, \mathrm{y}, \mathrm{z}$

$2-\mathrm{x}, 1 / 2+\mathrm{y}, 1 / 2-\mathrm{z}$

$3-\mathrm{x},-\mathrm{y},-\mathrm{z}$

$4 \mathrm{x}, 1 / 2-\mathrm{y}, 1 / 2+\mathrm{z}$

loop_

_atom_site_label

_atom_site_fract_x

_atom_site_fract_y

_atom_site_fract_z

$\begin{array}{lllll}\text { C1 } & 0.68836 & 0.09755 & 0.74154 & \# 1\end{array}$

N2 $\quad 0.77183 \quad 0.30198 \quad 0.84748 \quad$ \# 2

N3 $\quad 0.63983 \quad 0.10638 \quad 0.88190 \quad$ \# 3

H4 $0.57546 \quad 0.13071 \quad 0.62652 \quad$ \# 4

$\begin{array}{lllll}\mathrm{H}^{* 5} & 0.91712 & 0.25664 & 0.91132\end{array}$

N'6 $0.82878-0.10694 \quad 0.73057 \quad$ \#6

$\begin{array}{lllll}\text { O7 } & 0.79554 & -0.19872 & 0.60059 & \text { \# } 7\end{array}$

$\begin{array}{lllll}\text { O8 } & 0.96518 & -0.16617 & 0.85166 & \# 8\end{array}$

$\begin{array}{lllll}\text { H*9 } & 0.72988 & -0.02091 & 0.96010\end{array}$ \# 9

$\begin{array}{lllll}\text { \#XC1 } & 0.74760 & -0.02365 & 0.70352 & \text { \# } 10\end{array}$

$\begin{array}{lllll}\text { \#XN2 } & 0.73136 & 0.36079 & 0.84000 & \# 11\end{array}$

$\begin{array}{lllll}\text { \#XN3 } & 0.58717 & 0.14773 & 0.87287 & \# 12\end{array}$

$\begin{array}{lllll}\text { \#XH4 } & 0.56501 & 0.11842 & 0.59756\end{array}$

$\begin{array}{lllll}\text { \#XH*5 } & 0.92504 & 0.26154 & 0.91382 & \text { \# } 14\end{array}$

$\begin{array}{lllll}\text { \#XN'6 } & 0.81681 & -0.08677 & 0.72843 & \text { \# } 15\end{array}$

$\begin{array}{lllll}\text { \#XO7 } & 0.82311 & -0.25119 & 0.67553 & \text { \# } 16\end{array}$

$\begin{array}{lllll}\text { \#XO8 } & 0.95765 & -0.21818 & 0.78714\end{array}$

$\begin{array}{lllll}\text { \#XH*9 } & 0.72994 & -0.03181 & 0.96099\end{array}$

$\begin{array}{lllll}\text { \#XLP2+ } & 0.69538 & 0.31959 & 0.87288 & \text { \# } 19\end{array}$

$\begin{array}{lllll}\text { \#XLP2- } & 0.65667 & 0.21129 & 0.90382 & \text { \# } 20\end{array}$

$\begin{array}{lllll}\text { \#XLP3+ } & 0.63702 & 0.22898 & 0.81187 & \text { \#21 }\end{array}$

$\begin{array}{lllll}\text { \#XLP3- } & 0.67810 & 0.21219 & 0.88843 & \text { \#22 }\end{array}$

$\begin{array}{lllll}\text { \#XLP6+ } & 0.93088 & -0.22372 & 0.71674 & \text { \# } 23\end{array}$

$\begin{array}{lllll}\text { \#XLP6- } & 0.84238 & -0.23061 & 0.73251 & \text { \# } 24\end{array}$ 


$\begin{array}{lcccc}\text { \#XLP7+ } & 0.90089 & -0.24823 & 0.64805 & \text { \# 25 } \\ \text { \#XLP7- } & 0.72073 & -0.07929 & 0.60985 & \text { \#26 } \\ \text { \#XLP8+ } & 0.84627 & -0.11311 & 0.87275 & \text { \#27 } \\ \text { \#XLP8- } & 0.93983 & 0.02608 & 0.88093 & \text { \# } 28\end{array}$

\#END

\section{1,2-dinitrodiaziridine (cis-form)}

data $-3.53594 \mathrm{E}+01$

_chemical_name_systematic

;RAS DNDAZ_2_cis PVDZ

$\mathrm{E}($ total $)=-3.53594 \mathrm{E}+01 \mathrm{E}(\mathrm{coul})=-1.04726 \mathrm{E}+01 \mathrm{E}(\mathrm{vdW})=-2.48868 \mathrm{E}+01$ Density $=1.91017$

;

_cell_length_a 17.522

_cell_length_b 4.897

_cell_length_c 11.605

_cell_angle_alpha 90.00

_cell_angle_beta 110.55

_cell_angle_gamma 90.00

_cell_formula_units_Z 4

_symmetry_space_group_name_H-M 'P 21/C '

_symmetry_Int_Tables_number 14

loop

_symmetry_equiv_pos_as_xyz

$1 \mathrm{x}, \mathrm{y}, \mathrm{z}$

$2-\mathrm{x}, 1 / 2+\mathrm{y}, 1 / 2-\mathrm{z}$

$3-\mathrm{x},-\mathrm{y},-\mathrm{z}$

$4 \mathrm{x}, 1 / 2-\mathrm{y}, 1 / 2+\mathrm{z}$

loop_

_atom_site_label

_atom_site_fract_x

_atom_site_fract_y

_atom_site_fract_z

$\begin{array}{llll}\text { C1 } & 0.39791 & 0.43078 & 0.15381\end{array}$

$\mathrm{H} 2$ 


\begin{tabular}{|c|c|c|c|}
\hline $\mathrm{H} 3$ & $\begin{array}{lll}0.43271 & 0.43254 & 0 .\end{array}$ & .09207 & \# 3 \\
\hline N4 & $\begin{array}{lll}0.43971 & 0.52982 & 0 .\end{array}$ & .27637 & $\# 4$ \\
\hline N5 & $\begin{array}{llll}0.37666 & 0.70317 & 0 .\end{array}$ & .18894 & $\# 5$ \\
\hline N'6 & $\begin{array}{lll}0.29212 & 0.69023 & 0.2\end{array}$ & .20654 & $\# 6$ \\
\hline $\mathrm{O} 7$ & $\begin{array}{lll}0.26357 & 0.46949 & 0 .\end{array}$ & .21603 & \# 7 \\
\hline $\mathrm{O} 8$ & $\begin{array}{lll}0.26422 & 0.91423 & 0 .\end{array}$ & .20539 & \# 8 \\
\hline N'9 & $\begin{array}{lll}0.41936 & 0.38985 & 0.3\end{array}$ & .37532 & $\# 9$ \\
\hline $\mathrm{O} 10$ & $\begin{array}{llll}0.39953 & 0.53834 & 0\end{array}$ & 0.44326 & \# 10 \\
\hline O11 & $0.43351 \quad 0.14696 \quad 0$ & 0.38347 & \# 11 \\
\hline$\# \mathrm{XC1}$ & $0.38518 \quad 0.39026$ & 0.17189 & \# 12 \\
\hline \#XH2 & $0.34806 \quad 0.20265$ & 0.13749 & \# 13 \\
\hline \#XH3 & $0.44357 \quad 0.44202$ & 0.08679 & \# 14 \\
\hline$\# \mathrm{XN} 4$ & $0.48211 \quad 0.58201$ & 0.30413 & \# 15 \\
\hline \#XN5 & $0.38349 \quad 0.80890$ & 0.17269 & \# 16 \\
\hline \#XN'6 & $0.28055 \quad 0.72359$ & 0.19317 & \# 17 \\
\hline \#XO7 & $0.26448 \quad 0.52290$ & 0.21667 & \# 18 \\
\hline \#XO8 & $0.29315 \quad 0.92606$ & 0.18814 & \# 19 \\
\hline \#XN'9 & $0.42337 \quad 0.40749$ & 0.37681 & \# 20 \\
\hline \#XO10 & $0.41761 \quad 0.59813$ & 0.41860 & $\# 21$ \\
\hline \#XO11 & $0.42808 \quad 0.23413$ & 0.37781 & \# 22 \\
\hline \#XLP4+ & $0.40946 \quad 0.37889$ & 0.25276 & \# 23 \\
\hline \#XLP4- & $0.42039 \quad 0.49501$ & 0.25241 & \# 24 \\
\hline \#XLP5+ & $0.35361 \quad 0.64210$ & 0.17486 & \# 25 \\
\hline \#XLP5- & $0.37191 \quad 0.65524$ & 0.19727 & \# 26 \\
\hline \#XLP6+ & $0.26956 \quad 0.72158$ & 0.19087 & \# 27 \\
\hline \#XLP6- & $0.30607 \quad 0.77433$ & 0.22427 & \# 28 \\
\hline \#XLP7+ & $0.30811 \quad 0.64322$ & 0.25401 & \# 29 \\
\hline \#XLP7- & $0.31517 \quad 0.67019$ & 0.27394 & \# 30 \\
\hline \#XLP8+ & $0.23876 \quad 0.84246$ & $5 \quad 0.20263$ & \# 31 \\
\hline \#XLP8- & $0.23396 \quad 0.85217$ & 0.19597 & \# 32 \\
\hline \#XLP9+ & $\begin{array}{ll}0.39451 & 0.33909\end{array}$ & 0.35328 & \# 33 \\
\hline \#XLP9- & $0.43045 \quad 0.42021$ & 0.38253 & \# 34 \\
\hline \#XL10+ & $0.37495 \quad 0.38918$ & 0.40078 & \# 35 \\
\hline \#XL10- & $0.38776 \quad 0.44805$ & 0.44801 & \# 36 \\
\hline \#XL11+ & $0.42719 \quad 0.24062$ & 0.38344 & \# 37 \\
\hline
\end{tabular}




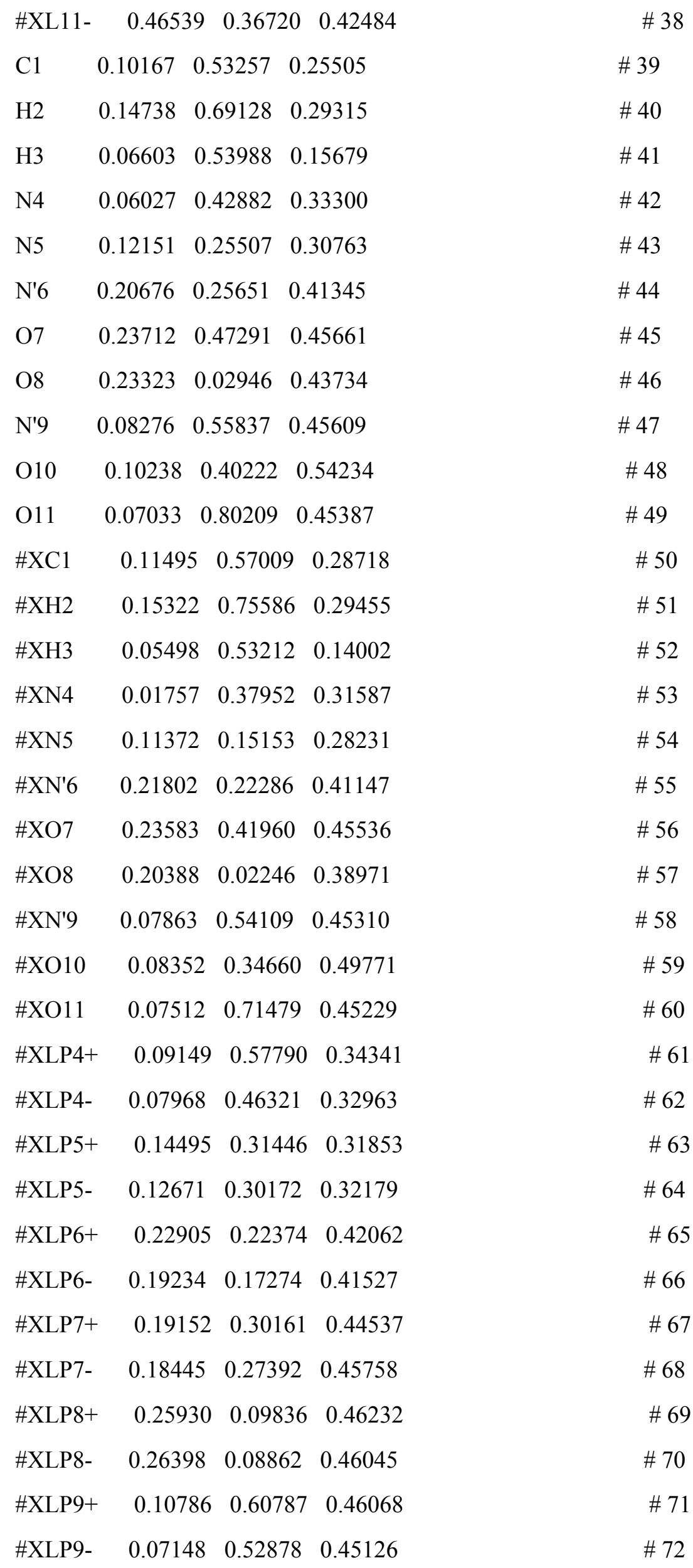




$\begin{array}{lllll}\text { \#XL10+ } & 0.12769 & 0.55171 & 0.52787 & \text { \#73 } \\ \text { \#XL10- } & 0.11490 & 0.49064 & 0.56097 & \text { \#74 } \\ \text { \#XL11+ } & 0.07603 & 0.70776 & 0.45876 & \text { \# 75 } \\ \text { \#XL11- } & 0.03718 & 0.58254 & 0.45839 & \# 76\end{array}$

\#END

\section{1,3-dinitrodiaziridine (cis-form)}

data $-2.40960 \mathrm{E}+01$

_chemical_name_systematic

;RAS DNDAZ_2i_cis1 PVDZ

$\mathrm{E}($ total $)=-2.40960 \mathrm{E}+01 \mathrm{E}(\mathrm{coul})=-1.09930 \mathrm{E}+01 \mathrm{E}(\mathrm{vdW})=-1.31031 \mathrm{E}+01$ Density $=1.88002$

;

_cell_length_a 5.995

_cell_length_b 10.059

_cell_length_c 11.694

_cell_angle_alpha 90.00

_cell_angle_beta 137.80

_cell_angle_gamma 90.00

_cell_formula_units_Z 4

_symmetry_space_group_name_H-M 'P 21/C '

_symmetry_Int_Tables_number 14

loop

_symmetry_equiv_pos_as_xyz

$1 \mathrm{x}, \mathrm{y}, \mathrm{z}$

$2-\mathrm{x}, 1 / 2+\mathrm{y}, 1 / 2-\mathrm{z}$

$3-\mathrm{x},-\mathrm{y},-\mathrm{z}$

$4 \mathrm{x}, 1 / 2-\mathrm{y}, 1 / 2+\mathrm{z}$

loop_

_atom_site_label

_atom_site_fract_x

_atom_site_fract_y

_atom_site_fract_z

$\begin{array}{lllll}\text { C1 } & 0.68091 & 0.75862 & 0.27382 & \# 1 \\ \text { N2 } & 0.71591 & 0.77169 & 0.16339 & \# 2\end{array}$




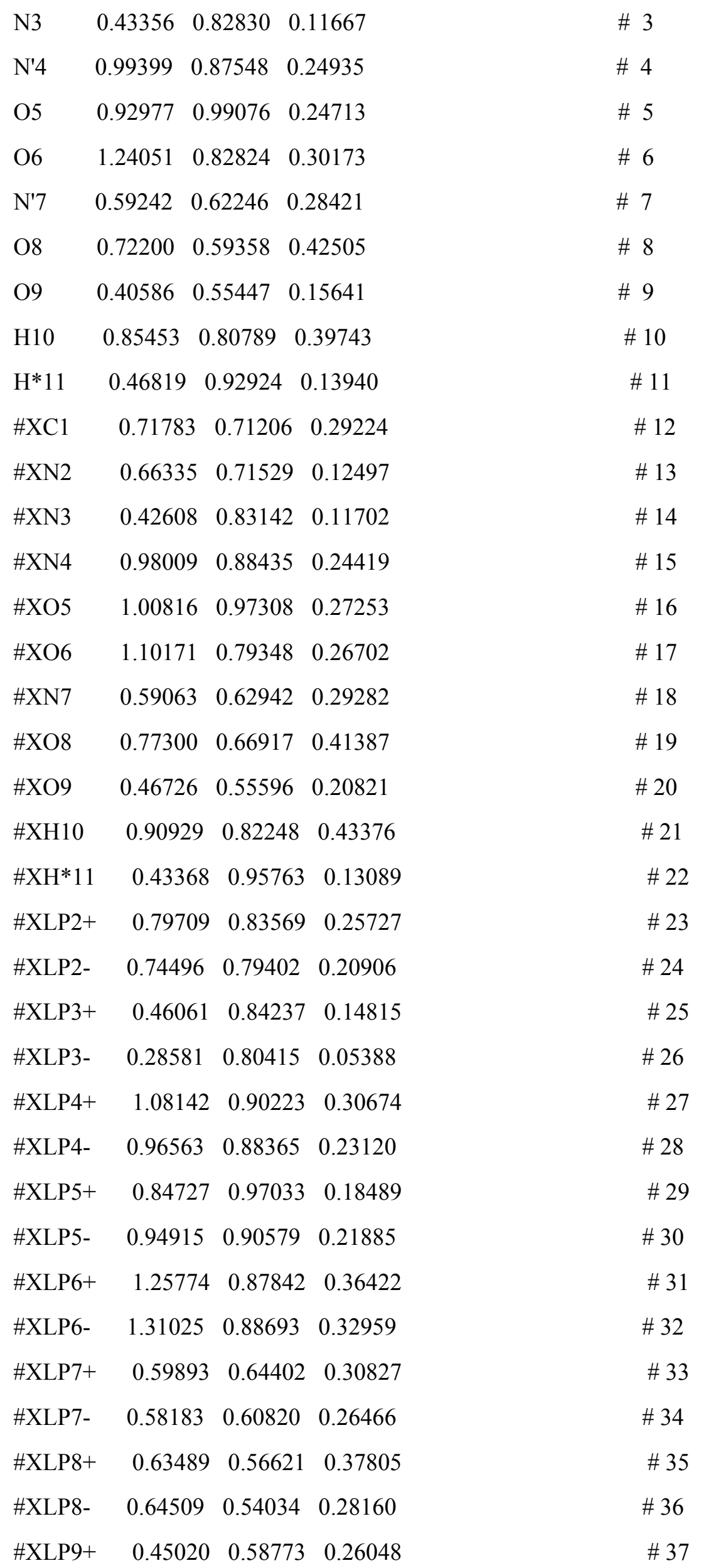


$\begin{array}{llll}\text { \#XLP9- } & 0.47516 & 0.58704 & 0.22072\end{array}$

\# 38

\#END

\section{3,3-dinitrodiaziridine (cis-form)}

data $-5.36517 \mathrm{E}+01$

_chemical_name_systematic

;RAS DNDAZ_2ii_cis PVDZ_Cs

$\mathrm{E}($ total $)=-5.36517 \mathrm{E}+01 \mathrm{E}($ coul $)=-2.43173 \mathrm{E}+01 \mathrm{E}(\mathrm{vdW})=-2.93344 \mathrm{E}+01$ Density $=2.00593$

;

_cell_length_a 5.707

_cell_length_b 29.763

_cell_length_c 5.550

_cell_angle_alpha 90.00

_cell_angle_beta 109.62

_cell_angle_gamma 90.00

_cell_formula_units_Z 4

_symmetry_space_group_name_H-M 'P 21/A '

_symmetry_Int_Tables_number 14

loop_

_symmetry_equiv_pos_as_xyz

$1 \mathrm{x}, \mathrm{y}, \mathrm{z}$

$21 / 2-x, 1 / 2+y,-z$

$3-\mathrm{x},-\mathrm{y},-\mathrm{z}$

$41 / 2+x, 1 / 2-y, z$

loop_

_atom_site_label

_atom_site_fract_x

_atom_site_fract_y

atom_site_fract_z

$\begin{array}{llll}\text { C1 } & 0.25970 & 0.44496 & 0.90754\end{array}$

\# 1

$\begin{array}{llll}\mathrm{N} 2 & 0.18878 & 0.48072 & 0.73085\end{array}$

\#2

$\begin{array}{lllll}\mathrm{N} 3 & 0.03976 & 0.43720 & 0.69915\end{array}$

\# 3

$\begin{array}{llll}\text { N'4 } & 0.49216 & 0.41802 & 0.92613\end{array}$

\# 4

$\begin{array}{llll}\text { O5 } & 0.52412 & 0.41105 & 0.72157\end{array}$

\# 5 


\begin{tabular}{|c|c|c|}
\hline O6 & $\begin{array}{lll}0.62385 & 0.40592 & 1.13682\end{array}$ & \# 6 \\
\hline $\mathrm{H}^{* 7}$ & $\begin{array}{lll}0.08262 & 0.41669 & 0.57073\end{array}$ & \# 7 \\
\hline N'8 & $\begin{array}{lll}0.24301 & 0.45109 & 1.17173\end{array}$ & $\# 8$ \\
\hline O9 & $\begin{array}{lll}0.34528 & 0.48435 & 1.28765\end{array}$ & $\# 9$ \\
\hline $\mathrm{O} 10$ & $\begin{array}{lll}0.13135 & 0.42187 & 1.24214\end{array}$ & \# 10 \\
\hline $\mathrm{H}^{*} 11$ & $0.29801 \quad 0.47958 \quad 0.61654$ & \# 11 \\
\hline$\# \mathrm{XC1}$ & $\begin{array}{lll}0.26451 & 0.44526 & 0.96227\end{array}$ & \# 12 \\
\hline$\# \mathrm{XN} 2$ & $\begin{array}{lll}0.14004 & 0.50099 & 0.74207\end{array}$ & \# 13 \\
\hline \#XN3 & $\begin{array}{lll}-0.07986 & 0.43677 & 0.69530\end{array}$ & \# 14 \\
\hline \#XN'4 & $\begin{array}{lll}0.51332 & 0.41536 & 0.91467\end{array}$ & \# 15 \\
\hline \#XO5 & $\begin{array}{lll}0.51731 & 0.41338 & 0.81854\end{array}$ & \# 16 \\
\hline \#XO6 & $\begin{array}{lll}0.60588 & 0.40630 & 1.02749\end{array}$ & \# 17 \\
\hline$\# \mathrm{XH}^{*} 7$ & $\begin{array}{lll}0.05798 & 0.41336 & 0.54210\end{array}$ & \# 18 \\
\hline \#XN'8 & $\begin{array}{lll}0.23607 & 0.45491 & 1.36193\end{array}$ & \# 19 \\
\hline \#ХO9 & $\begin{array}{lll}0.27011 & 0.46560 & 1.37229\end{array}$ & \# 20 \\
\hline \#XO10 & $\begin{array}{lll}0.19854 & 0.44470 & 1.35707\end{array}$ & \#21 \\
\hline$\# \mathrm{XH}^{*} 11$ & $\begin{array}{lll}0.30175 & 0.48454 & 0.59394\end{array}$ & \# 22 \\
\hline \#XLP1+ & $\begin{array}{lll}0.43440 & 0.42509 & 1.01449\end{array}$ & \# 23 \\
\hline \#XLP1- & $\begin{array}{lll}0.24666 & 0.44126 & 0.92088\end{array}$ & $\# 24$ \\
\hline \#XLP2+ & $\begin{array}{lll}0.23339 & 0.45913 & 1.05672\end{array}$ & \# 25 \\
\hline \#XLP2- & $\begin{array}{lll}0.33280 & 0.48111 & 1.14339\end{array}$ & \#26 \\
\hline \#XLP3+ & $\begin{array}{lll}0.19037 & 0.44657 & 1.04757\end{array}$ & \# 27 \\
\hline \#XLP3- & $\begin{array}{lll}0.13078 & 0.42212 & 1.10042\end{array}$ & \# 28 \\
\hline \#XLP4+ & $\begin{array}{lll}0.46697 & 0.40057 & 0.95766\end{array}$ & \# 29 \\
\hline \#XLP4- & $\begin{array}{lll}0.56044 & 0.41599 & 0.94159\end{array}$ & $\# 30$ \\
\hline \#XLP8+ & $\begin{array}{lll}0.21881 & 0.45419 & 1.14886\end{array}$ & \# 31 \\
\hline \#XLP8- & $-\quad \begin{array}{lll}0.19533 & 0.44954 & 0.93225\end{array}$ & \# 32 \\
\hline $\mathrm{C} 1$ & $\begin{array}{lll}0.45038 & 0.18701 & 0.78919\end{array}$ & \# 33 \\
\hline $\mathrm{N} 2$ & $\begin{array}{lll}0.61072 & 0.21364 & 0.98648\end{array}$ & $\# 34$ \\
\hline N3 & $\begin{array}{lll}0.62057 & 0.16237 & 0.98946\end{array}$ & \# 35 \\
\hline $\mathrm{N}^{\prime} 4$ & $\begin{array}{lll}0.17479 & 0.18526 & 0.75750\end{array}$ & \# 36 \\
\hline O5 & $\begin{array}{lll}0.12869 & 0.18491 & 0.95801\end{array}$ & \# 37 \\
\hline O6 & $\begin{array}{lll}0.02657 & 0.18438 & 0.54155\end{array}$ & \# 38 \\
\hline $\mathrm{H}^{* 7}$ & $\begin{array}{lll}0.52756 & 0.15032 & 1.10582\end{array}$ & \# 39 \\
\hline N'8 & $\begin{array}{lll}0.48068 & 0.18727 & 0.52881\end{array}$ & $\# 40$ \\
\hline
\end{tabular}




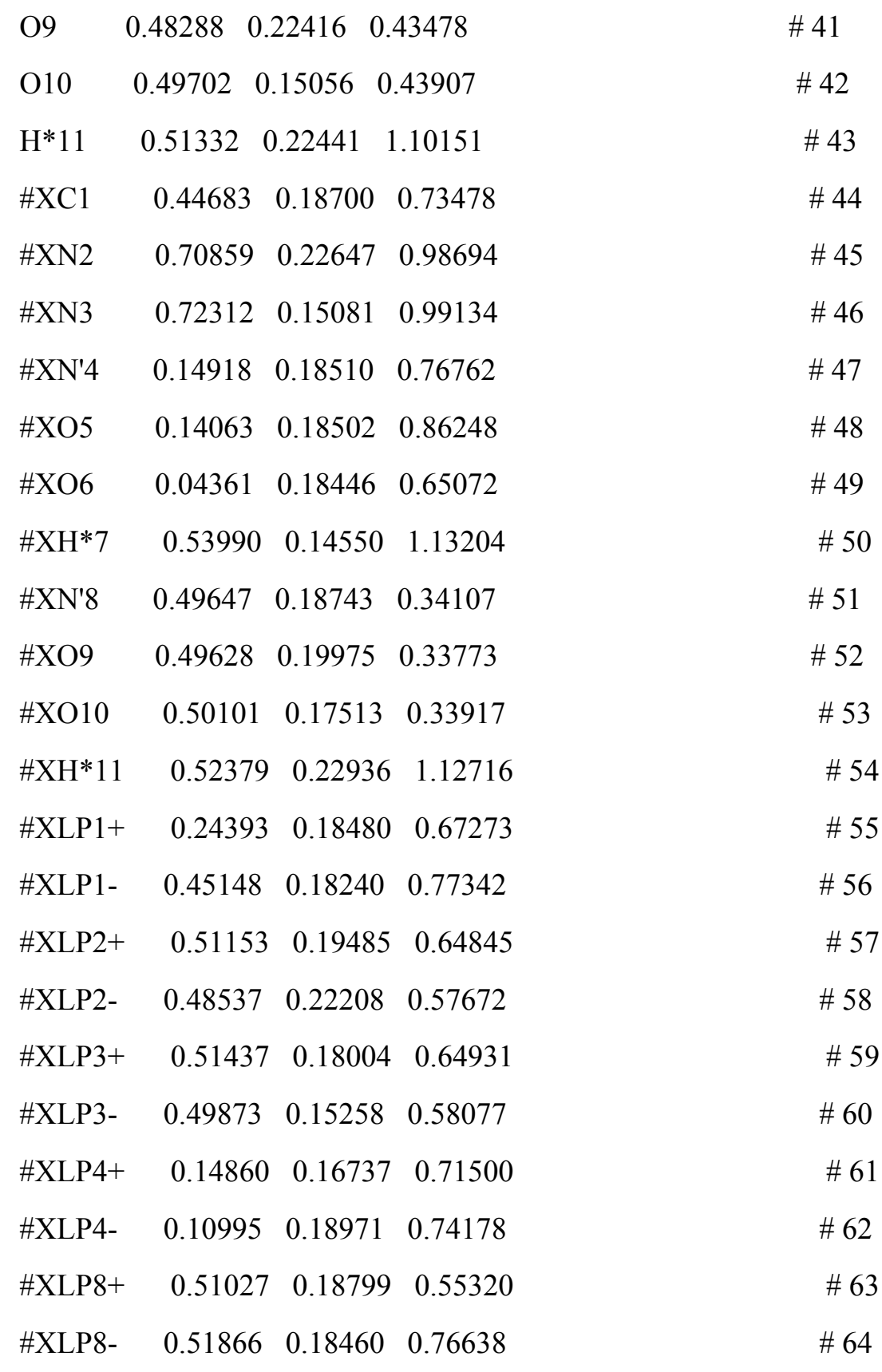

\#END

\section{1,2,3-trinitrodiaziridine (cis-form)}

data $-2.10576 \mathrm{E}+01$

_chemical_name_systematic

;RAS DNDAZ_3_cis1 PVDZ

$\mathrm{E}($ total $)=-2.10576 \mathrm{E}+01 \mathrm{E}(\mathrm{coul})=-5.53337 \mathrm{E}+00 \mathrm{E}(\mathrm{vdW})=-1.55242 \mathrm{E}+01$ Density $=1.95444$

;

_cell_length_a 5.887

_cell_length_b 21.327 
_cell_length_c 4.847

_cell_angle_alpha 90.00

_cell_angle_beta 90.00

_cell_angle_gamma 90.00

_cell_formula_units_Z 4

_symmetry_space_group_name_H-M 'P 212121'

_symmetry_Int_Tables_number 19

loop_

_symmetry_equiv_pos_as_xyz

$1 \mathrm{x}, \mathrm{y}, \mathrm{z}$

$21 / 2+x, 1 / 2-y,-z$

$3-\mathrm{x}, 1 / 2+\mathrm{y}, 1 / 2-\mathrm{z}$

$41 / 2-x,-y, 1 / 2+z$

loop_

_atom_site_label

_atom_site_fract_x

_atom_site_fract_y

_atom_site_fract_z

$\begin{array}{lllll}\text { C1 } & -0.01927 & -0.33960 & 0.23713 & \# 1\end{array}$

$\begin{array}{lllll}\mathrm{N} 2 & 0.06562 & -0.39439 & 0.36605 & \# 2\end{array}$

$\begin{array}{lllll}\text { N3 } & -0.11275 & -0.35840 & 0.50519 & \text { \# } 3\end{array}$

$\begin{array}{lllll}\text { N'4 } & -0.36588 & -0.38489 & 0.45772 & \# 4\end{array}$

$\begin{array}{lllll}\text { O5 } & -0.47060 & -0.38445 & 0.66852 & \# 5\end{array}$

$\begin{array}{lllll}\text { O6 } & -0.42044 & -0.40035 & 0.22729 & \# 6\end{array}$

$\begin{array}{lllll}\text { N'7 } & 0.00360 & -0.45519 & 0.22313 & \text { \# } 7\end{array}$

$\begin{array}{lllll}\text { O8 } & -0.08664 & -0.49339 & 0.36964 & \# 8\end{array}$

$\begin{array}{lllll}\text { O9 } & 0.07312 & -0.45915 & -0.01027\end{array}$

$\begin{array}{lllll}\mathrm{N}^{\prime} 10 & 0.13027 & -0.28219 & 0.23835 & \# 10\end{array}$

$\begin{array}{lllll}011 & 0.06675 & -0.24062 & 0.08226 & \text { \# } 11\end{array}$

$\begin{array}{lllll}\text { O12 } & 0.29378 & -0.28172 & 0.39135 & \# 12\end{array}$

$\begin{array}{lllll}\text { H13 } & -0.12488 & -0.34203 & 0.05278 & \# 13\end{array}$

$\begin{array}{lllll}\text { \#XC1 } & -0.03511 & -0.33679 & 0.33731 & \text { \# } 14\end{array}$

$\begin{array}{lllll}\text { \#XN2 } & 0.19850 & -0.38692 & 0.48849 & \text { \# } 15\end{array}$

$\begin{array}{lllll}\text { \#XN3 } & -0.10589 & -0.35338 & 0.61286 & \text { \# } 16\end{array}$

$\begin{array}{lllll}\text { \#XN'4 } & -0.45121 & -0.36439 & 0.48440 & \text { \# } 17\end{array}$ 


\begin{tabular}{|c|c|c|c|}
\hline \#XO5 & $-0.44330-0.38137$ & 0.54266 & \# 18 \\
\hline \#XO6 & $-0.45396-0.39113$ & 0.21242 & \# 19 \\
\hline \#XN'7 & $0.06648-0.46688$ & 0.18400 & \# 20 \\
\hline \#XO8 & $-0.06852-0.51247$ & 0.30325 & \# 21 \\
\hline \#XO9 & $0.06338-0.46723$ & 0.09028 & \# 22 \\
\hline \#XN'10 & $0.11819-0.28851$ & 0.32338 & $\# 23$ \\
\hline \#XO11 & $0.16601 \quad-0.23194$ & 0.16360 & \# 24 \\
\hline \#XO12 & $0.29239-0.25935$ & 0.37845 & $\# 25$ \\
\hline \#XH13 & $-0.11486-0.33895$ & 0.00207 & \# 26 \\
\hline \#XLP2+ & $0.01255-0.37303$ & 0.40078 & \# 27 \\
\hline \#XLP2- & $-0.09200-0.37093$ & 0.49186 & \# 28 \\
\hline \#XLP3+ & $0.02497-0.38421$ & 0.38486 & \# 29 \\
\hline \#XLP3- & $-0.09564-0.37831$ & 0.53441 & \# 30 \\
\hline \#XLP4+ & $-0.15338-0.42921$ & $1 \quad 0.29185$ & \# 31 \\
\hline \#XLP4- & $-0.23443-0.41151$ & 0.38054 & \# 32 \\
\hline \#XLP5+ & $-0.10651-0.45143$ & 30.40043 & \# 33 \\
\hline \#XLP5- & $-0.23566 \quad-0.44161$ & 0.45831 & \# 34 \\
\hline \#XLP6+ & $-0.14372-0.43869$ & 0.17153 & $\# 35$ \\
\hline \#XLP6- & $-0.41106-0.43140$ & 0.27760 & \# 36 \\
\hline \#XLP7+ & $-0.12174-0.42780$ & 0.35283 & $\# 37$ \\
\hline \#XLP7- & $-0.19031 \quad-0.41067$ & 0.42722 & \#38 \\
\hline \#XLP8+ & $-0.11987-0.44300$ & 0.46732 & \# 39 \\
\hline \#XLP8- & $-0.38743 \quad-0.42264$ & 0.48084 & $\# 40$ \\
\hline \#XLP9+ & $\begin{array}{ll}-0.02849 & -0.39531\end{array}$ & 0.20716 & \# 41 \\
\hline \#XLP9- & $-0.23939 \quad-0.40224$ & 0.26871 & \# 42 \\
\hline \#XL10+ & $0.15643-0.29623$ & 0.22507 & \# 43 \\
\hline \#XL10- & $0.18468-0.26201$ & 0.34890 & $\# 44$ \\
\hline \#XL11+ & $0.22473-0.24700$ & 0.25084 & \# 45 \\
\hline \#XL11- & $-0.01102-0.27257$ & 0.06348 & $\# 46$ \\
\hline \#XL12+ & $0.23988-0.29449$ & 0.38232 & \# 47 \\
\hline \#XL12- & $0.33426-0.27367$ & 0.45753 & $\# 48$ \\
\hline
\end{tabular}

1,3,3-trinitrodiaziridine (cis-form)

data_01474_-2.32432E+01 
_chemical_name_systematic

;RAS DNDAZ_3i_cis PVDZ

$\mathrm{E}($ total $)=-2.32432 \mathrm{E}+01 \mathrm{E}($ coul $)=-5.96104 \mathrm{E}+00 \mathrm{E}(\mathrm{vdW})=-1.72821 \mathrm{E}+01$ Density $=2.05563$

_cell_length_a 10.286

_cell_length_b 10.342

_cell_length_c 5.439

_cell_angle_alpha 90.00

cell_angle_beta 90.00

_cell_angle_gamma 90.00

_cell_formula_units_Z 4

_symmetry_space_group_name_H-M 'P NA21 '

_symmetry_Int_Tables_number 33

loop

_symmetry_equiv_pos_as_xyz

$1 \mathrm{x}, \mathrm{y}, \mathrm{z}$

$21 / 2-x, 1 / 2+y, 1 / 2+z$

$31 / 2+x, 1 / 2-y, z$

$4-\mathrm{x},-\mathrm{y}, 1 / 2+\mathrm{z}$

loop_

_atom_site_label

_atom_site_fract_x

_atom_site_fract_y

_atom_site_fract_z

$\begin{array}{lllll}\text { C1 } & 0.17292 & 0.37443 & 0.49993 & \# 1 \\ \text { N2 } & 0.23718 & 0.49585 & 0.53443 & \# 2 \\ \text { N3 } & 0.26420 & 0.38246 & 0.69321 & \# 3 \\ \text { N'4 } & 0.34186 & 0.52236 & 0.34035 & \# 4 \\ \text { O5 } & 0.45222 & 0.50363 & 0.40637 & \# 5 \\ \text { O6 } & 0.29939 & 0.56889 & 0.15398 & \# 6 \\ \text { N'7 } & 0.03036 & 0.36344 & 0.56770 & \# 7 \\ \text { O8 } & -0.03789 & 0.45724 & 0.53246 & \# 8 \\ \text { O9 } & 0.00086 & 0.25857 & 0.65362 & \# 9 \\ \text { N'10 } & 0.20004 & 0.29385 & 0.27131 & \# 10\end{array}$




\begin{tabular}{|c|c|c|c|}
\hline O11 & $\begin{array}{lll}0.31227 & 0.25737 & 0\end{array}$ & 0.24712 & \# 11 \\
\hline $\mathrm{O} 12$ & $\begin{array}{lll}0.10853 & 0.27512 & 0\end{array}$ & 0.13533 & \# 12 \\
\hline $\mathrm{H}^{*} 13$ & $\begin{array}{lll}0.35079 & 0.33979 & 0\end{array}$ & 0.64103 & $\# 13$ \\
\hline$\# \mathrm{XC1}$ & $0.18419 \quad 0.36237$ & 0.49530 & \# 14 \\
\hline$\# \mathrm{XN} 2$ & $0.22904 \quad 0.49019$ & 0.53409 & $\# 15$ \\
\hline$\# \mathrm{XN} 3$ & $0.24621 \quad 0.39642$ & 0.80348 & $\# 16$ \\
\hline \#XN4 & $0.35316 \quad 0.56055$ & 0.36208 & $\# 17$ \\
\hline \#XO5 & $0.39817 \quad 0.51213$ & 0.49764 & $\# 18$ \\
\hline \#XO6 & $0.34048 \quad 0.54727$ & 0.21765 & \# 19 \\
\hline$\# \mathrm{XN7}$ & $0.03328 \quad 0.36479$ & 0.58476 & $\# 20$ \\
\hline \#XO8 & $-0.05015 \quad 0.41435$ & 0.56617 & \# 21 \\
\hline$\#$ XO9 & $0.11098 \quad 0.28051$ & 0.59690 & \# 22 \\
\hline \#XN10 & $0.20899 \quad 0.29083$ & 0.28917 & $\# 23$ \\
\hline \#XO11 & $0.28544 \quad 0.23919$ & 0.34447 & \# 24 \\
\hline \#XO12 & $0.16206 \quad 0.24846$ & 0.06791 & $\# 25$ \\
\hline$\# \mathrm{XH}^{*} 13$ & $0.38963 \quad 0.32063$ & 30.68776 & $\# 26$ \\
\hline \#XLP2+ & $0.23047 \quad 0.53807$ & $7 \quad 0.62844$ & $\# 27$ \\
\hline \#XLP2- & $0.24767 \quad 0.47890$ & 0.55813 & \# 28 \\
\hline \#XLP3+ & $0.15779 \quad 0.47471$ & 0.49275 & \# 29 \\
\hline \#XLP3- & $0.21142 \quad 0.43166$ & 0.61524 & \# 30 \\
\hline \#XLP4+ & $0.34946 \quad 0.53937$ & $7 \quad 0.38287$ & \# 31 \\
\hline \#XLP4- & $0.35326 \quad 0.48872$ & 0.37403 & \# 32 \\
\hline \#XLP5+ & $0.41704 \quad 0.58677$ & $7 \quad 0.27902$ & $\# 33$ \\
\hline \#XLP5- & $0.44179 \quad 0.54806$ & 0.31569 & \# 34 \\
\hline \#XLP6+ & $0.36785 \quad 0.49901$ & 0.22765 & $\# 35$ \\
\hline \#XLP6- & $0.36914 \quad 0.48199$ & 0.35448 & \# 36 \\
\hline \#XLP7+ & $0.02160 \quad 0.36578$ & 0.57418 & $\# 37$ \\
\hline \#XLP7- & $0.04251 \quad 0.34152$ & 0.58461 & \# 38 \\
\hline \#XLP8+ & $-0.00791 \quad 0.40291$ & 10.67145 & $\# 39$ \\
\hline \#XLP8- & $0.00162 \quad 0.38547$ & 0.68493 & $\# 40$ \\
\hline \#XLP9+ & $-0.03104 \quad 0.35855$ & $5 \quad 0.53673$ & $\# 41$ \\
\hline \#XLP9- & $-0.05173 \quad 0.27531$ & 0.66533 & $\# 42$ \\
\hline \#XL10+ & $0.20630 \quad 0.30209$ & 0.24333 & \# 43 \\
\hline \#XL10- & $0.21655 \quad 0.27051$ & 0.34853 & $\# 44$ \\
\hline \#XL11+ & $0.21276 \quad 0.27524$ & 0.12305 & \# 45 \\
\hline
\end{tabular}




$\begin{array}{lllll}\text { \#XL11- } & 0.29770 & 0.24964 & 0.14060 & \text { \# } 46 \\ \text { \#XL12+ } & 0.13603 & 0.29221 & 0.21482 & \text { \# } 47 \\ \text { \#XL12- } & 0.18760 & 0.21544 & 0.26125 & \text { \# 48 }\end{array}$

\#END

\section{1,2,3,3-tetranitrodiaziridine (cis-form)}

data $-2.16182 \mathrm{E}+01$

_chemical_name_systematic

;RAS DNDAZ_4_cis PVDZ_Cs

$E($ total $)=-2.16182 E+01 E($ coul $)=-2.51569 E+00 E(v d W)=-1.91026 E+01$ Density $=2.06975$ ;

_cell_length_a 5.732

_cell_length_b 12.349

_cell_length_c 10.446

_cell_angle_alpha 90.00

_cell_angle_beta 103.48

_cell_angle_gamma 90.00

_cell_formula_units_Z 4

_symmetry_space_group_name_H-M 'P 21/N '

_symmetry_Int_Tables_number 14

loop_

_symmetry_equiv_pos_as_xyz

$1 \mathrm{x}, \mathrm{y}, \mathrm{z}$

$21 / 2-x, 1 / 2+y, 1 / 2-z$

$3-\mathrm{x},-\mathrm{y},-\mathrm{z}$

$41 / 2+x, 1 / 2-y, 1 / 2+z$

loop_

_atom_site_label

_atom_site_fract_x

_atom_site_fract_y

_atom_site_fract_z

$\begin{array}{llll}\text { C1 } & -0.56203 & -0.14202 & -0.29101\end{array}$

\# 1

$\begin{array}{llll}\mathrm{N} 2 & -0.55065 & -0.12910 & -0.15439\end{array}$

\# 2

N3

$\begin{array}{lll}-0.42345 & -0.05407 & -0.22571\end{array}$

\# 3 


\begin{tabular}{|c|c|c|}
\hline $\mathrm{N}^{\prime} 4$ & $\begin{array}{lll}-0.51480 & 0.06287 & -0.27374\end{array}$ & $\# 4$ \\
\hline O5 & $\begin{array}{lll}-0.55130 & 0.12176 & -0.18994\end{array}$ & \# 5 \\
\hline O6 & $\begin{array}{lll}-0.50493 & 0.07822 & -0.38587\end{array}$ & $\# 6$ \\
\hline $\mathrm{N}^{\prime} 7$ & $\begin{array}{lll}-0.79524 & -0.10256 & -0.11649\end{array}$ & \# 7 \\
\hline O8 & $\begin{array}{lll}-0.93563 & -0.17584 & -0.14437\end{array}$ & $\# 8$ \\
\hline O9 & $\begin{array}{lll}-0.79517 & -0.02209 & -0.05320\end{array}$ & $\# 9$ \\
\hline N'10 & $-0.43055-0.23724-0.33381$ & \# 10 \\
\hline $\mathrm{O} 11$ & $-0.29116-0.21434-0.40123$ & \# 11 \\
\hline $\mathrm{O} 12$ & $-0.47952-0.32545-0.29561$ & \# 12 \\
\hline $\mathrm{N}^{\prime} 13$ & $\begin{array}{ccc}-0.79688 & -0.12241 & -0.39469\end{array}$ & $\# 13$ \\
\hline $\mathrm{O} 14$ & $\begin{array}{lll}-0.83620 & -0.18291 & -0.48838\end{array}$ & \# 14 \\
\hline $\mathrm{O} 15$ & $\begin{array}{lll}-0.91935 & -0.04762 & -0.37147\end{array}$ & \# 15 \\
\hline$\# \mathrm{XC1}$ & $\begin{array}{lll}-0.60036 & -0.13192 & -0.29967\end{array}$ & \# 16 \\
\hline$\# \mathrm{XN} 2$ & $\begin{array}{lll}-0.56140 & -0.08703 & -0.09547\end{array}$ & \# 17 \\
\hline$\# \mathrm{XN} 3$ & $\begin{array}{lll}-0.41829 & -0.00261 & -0.17571\end{array}$ & $\# 18$ \\
\hline \#XN'4 & $\begin{array}{llll}-0.53055 & 0.13870 & -0.30099\end{array}$ & \# 19 \\
\hline \#XO5 & $\begin{array}{llll}-0.54476 & 0.15685 & -0.26466\end{array}$ & \# 20 \\
\hline \#XO6 & $\begin{array}{lll}-0.52324 & 0.13495 & -0.33243\end{array}$ & \# 21 \\
\hline \#XN'7 & $\begin{array}{lll}-0.93210 & -0.09817 & -0.07584\end{array}$ & \# 22 \\
\hline \#XO8 & $\begin{array}{lll}-0.95898 & -0.12208 & -0.08810\end{array}$ & \# 23 \\
\hline \#ХO9 & $\begin{array}{lll}-0.92164 & -0.06547 & -0.05333\end{array}$ & \# 24 \\
\hline \#XN'10 & $\begin{array}{lll}-0.36256 & -0.28058 & -0.34888\end{array}$ & \# 25 \\
\hline \#XO11 & $\begin{array}{lll}-0.30769 & -0.26776 & -0.37619\end{array}$ & \#26 \\
\hline \#XO12 & $\begin{array}{lll}-0.38772 & -0.31497 & -0.33131\end{array}$ & \# 27 \\
\hline \#XN'13 & $\begin{array}{lll}-0.94362 & -0.10572 & -0.45414\end{array}$ & \# 28 \\
\hline \#XO14 & $\begin{array}{lll}-0.92307 & -0.13863 & -0.48242\end{array}$ & \# 29 \\
\hline \#XO15 & $\begin{array}{lll}-0.96075 & -0.07122 & -0.42212\end{array}$ & \# 30 \\
\hline \#XLP1+ & $\begin{array}{lll}-0.56793 & -0.11457 & -0.26480\end{array}$ & \#3 \\
\hline \#XLP1- & $\begin{array}{lll}-0.60690 & -0.09121 & -0.25731\end{array}$ & \# 32 \\
\hline \#XLP2+ & $-0.52257-0.13640-0.11425$ & \#3. \\
\hline \#XLP2- & $\begin{array}{lll}-0.56063 & -0.10186 & -0.11394\end{array}$ & \# 34 \\
\hline \#XLP3+ & $-0.35812-0.03940-0.20646$ & \# 35 \\
\hline \#XLP3- & $\begin{array}{lll}-0.41878 & -0.01819 & -0.19348\end{array}$ & \#36 \\
\hline \#XLP4+ & $\begin{array}{lll}-0.41558 & -0.15317 & -0.34245\end{array}$ & \# 37 \\
\hline \#XLP4- & $\begin{array}{llll}-0.51324 & 0.02279 & -0.30865\end{array}$ & \# 38 \\
\hline
\end{tabular}




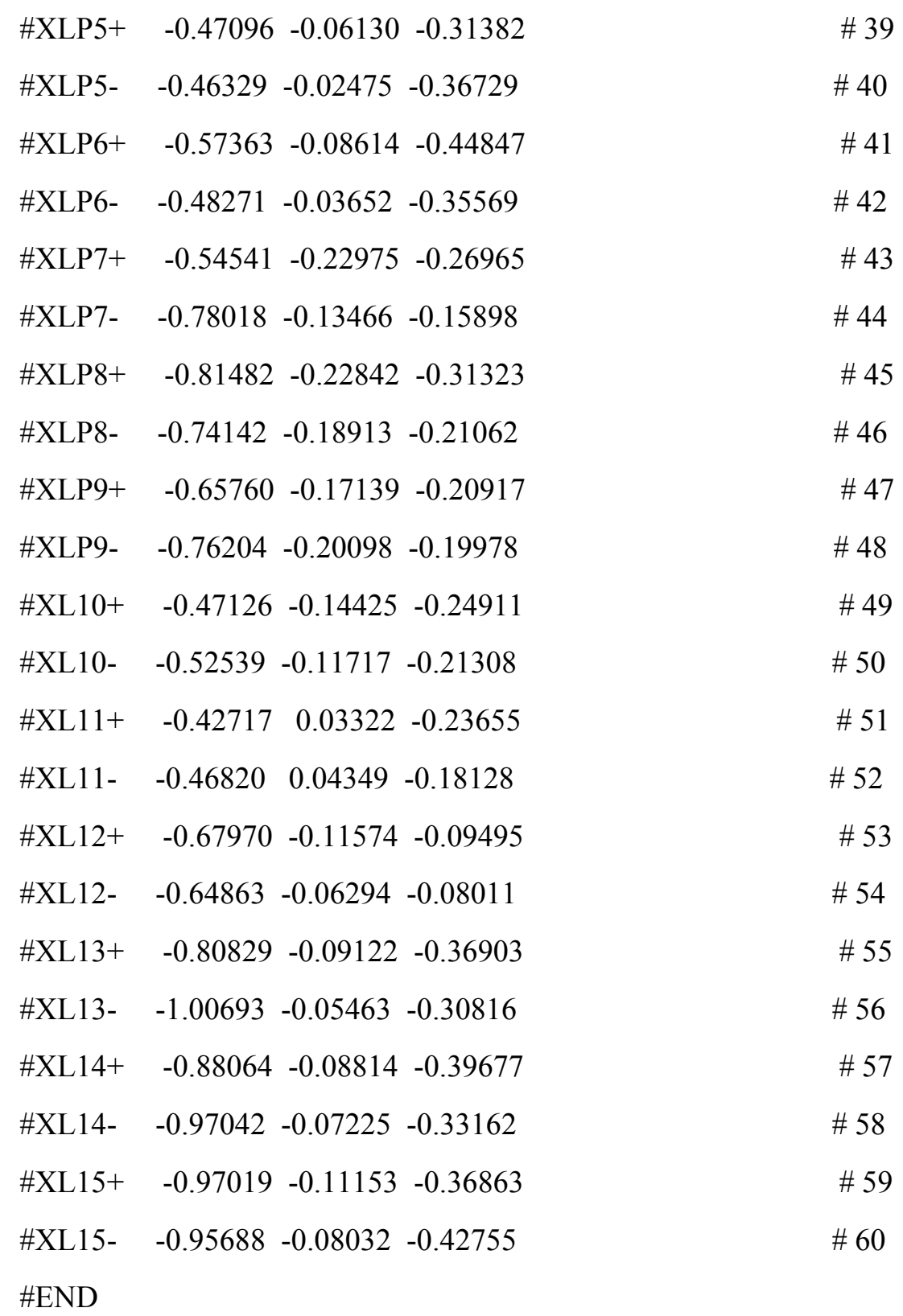

\section{1-nitrodiaziridine (trans-form)}

data__ $-1.95105 \mathrm{E}+01$

_chemical_name_systematic

;RAS DNDAZ_1 PVDZ

$E($ total $)=-1.95105 E+01 E($ coul $)=-9.50859 E+00 \quad E(v d W)=-1.00019 E+01$ Density $=1.65226$

;

_cell_length_a 7.352

_cell_length_b 9.761

_cell_length_c 9.980

_cell_angle_alpha 90.00 
_cell_angle_beta 90.00

_cell_angle_gamma 90.00

cell_formula_units_Z 8

_symmetry_space_group_name_H-M 'P BCA '

_symmetry_Int_Tables_number 61

loop

_symmetry_equiv_pos_as_xyz

$1 \mathrm{x}, \mathrm{y}, \mathrm{z}$

$21 / 2-x, 1 / 2+y, z$

$3 \mathrm{x}, 1 / 2-\mathrm{y}, 1 / 2+\mathrm{z}$

4 1/2-x,-y, $1 / 2+z$

$5-\mathrm{x},-\mathrm{y},-\mathrm{z}$

$61 / 2+x, 1 / 2-y,-z$

$7-\mathrm{x}, 1 / 2+\mathrm{y}, 1 / 2-\mathrm{z}$

$81 / 2+x, y, 1 / 2-z$

loop_

_atom_site_label

_atom_site_fract_x

atom_site_fract_y

_atom_site_fract_z

C1 $\quad 0.90150 \quad 0.66175-0.12055$

\# 1

$\begin{array}{llll}\mathrm{N} 2 & 0.73675 & 0.58503 & -0.09496\end{array}$

\# 2

N3 $\quad 0.89516 \quad 0.51561 \quad-0.15190$

\# 3

$\begin{array}{llll}\text { N'4 } & 0.71334 & 0.54557 & 0.04681\end{array}$

\# 4

$\begin{array}{llll}\text { O5 } & 0.69275 & 0.42466 & 0.06863\end{array}$

\# 5

O6

$\begin{array}{lll}0.70268 & 0.64104 & 0.12504\end{array}$

\# 6

$\mathrm{H} 7$

$\begin{array}{llll}0.98773 & 0.68825 & -0.03538\end{array}$

\# 7

$\begin{array}{llll}\mathrm{H}^{*} 8 & 0.86230 & 0.49881 & -0.25010\end{array}$

\# 8

H9 $\quad 0.88917 \quad 0.73884-0.19945$

\# 9

$\begin{array}{lllll}\text { \#XC1 } & 0.90435 & 0.66018 & -0.12007\end{array}$

\# 10

$\begin{array}{llll}\# X N 2 & 0.63769 & 0.59438 & -0.13534\end{array}$

\# 11

$\begin{array}{llll}\text { \#XN3 } & 0.92583 & 0.48365 & -0.11923\end{array}$

\# 12

$\begin{array}{llll}\text { \#XN'4 } & 0.69145 & 0.54768 & 0.02551\end{array}$

\# 13

$\begin{array}{llll}\text { \#XO5 } & 0.72831 & 0.44727 & 0.05363\end{array}$

\# 14

$\begin{array}{llll}\text { \#XO6 } & 0.72887 & 0.62622 & 0.08744\end{array}$

\# 15 


$\begin{array}{lcccc}\text { \#XH7 } & 1.00409 & 0.68682 & -0.01117 & \# 16 \\ \text { \#XH*8 } & 0.86343 & 0.48875 & -0.25980 & \# 17 \\ \text { \#XH9 } & 0.87454 & 0.77104 & -0.23410 & \# 18 \\ \text { \#XLP2+ } & 0.79354 & 0.57554 & -0.06639 & \# 19 \\ \text { \#XLP2- } & 0.82470 & 0.56922 & -0.05152 & \# 20 \\ \text { \#XLP3+ } & 0.84905 & 0.52072 & -0.18085 & \# 21 \\ \text { \#XLP3- } & 0.91320 & 0.48308 & -0.12479 & \# 22 \\ \text { \#XLP4+ } & 0.65125 & 0.54656 & 0.05644 & \# 23 \\ \text { \#XLP4- } & 0.77973 & 0.52896 & 0.07903 & \# 24 \\ \text { \#XLP5+ } & 0.68456 & 0.44095 & 0.00543 & \# 25 \\ \text { \#XLP5- } & 0.69038 & 0.44719 & 0.10476 & \# 26 \\ \text { \#XLP6+ } & 0.71819 & 0.65435 & 0.05759 & \# 27 \\ \text { \#XLP6- } & 0.68955 & 0.60095 & 0.14234 & \# 28 \\ \text { \#END } & & & & \end{array}$

\section{3-nitrodiaziridine (trans-form)}

data $-4.70678 \mathrm{E}+01$

_chemical_name_systematic

;RAS DNDAZ_1i PVDZ

$\mathrm{E}($ total $)=-4.70678 \mathrm{E}+01 \mathrm{E}(\mathrm{coul})=-2.75718 \mathrm{E}+01 \mathrm{E}(\mathrm{vdW})=-1.94960 \mathrm{E}+01$ Density $=1.92270$

;

_cell_length_a 4.815

_cell_length_b 13.196

_cell_length_c 9.685

_cell_angle_alpha 90.00

_cell_angle_beta 90.00

_cell_angle_gamma 90.00

_cell_formula_units_Z 4

_symmetry_space_group_name_H-M 'P CA21 '

_symmetry_Int_Tables_number 29

loop_

_symmetry_equiv_pos_as_xyz

$1 \mathrm{x}, \mathrm{y}, \mathrm{z}$

$21 / 2-x, y, 1 / 2+z$ 


\begin{tabular}{|c|c|c|}
\hline \multicolumn{3}{|c|}{$31 / 2+x,-y, z$} \\
\hline \multicolumn{3}{|c|}{$4-x,-y, 1 / 2+z$} \\
\hline \multicolumn{3}{|l|}{ loop_ } \\
\hline \multicolumn{3}{|c|}{ atom_site_label } \\
\hline \multicolumn{3}{|c|}{ _atom_site_fract_x } \\
\hline \multicolumn{3}{|c|}{ atom_site_fract_y } \\
\hline \multicolumn{3}{|c|}{ _atom_site_fract_z } \\
\hline $\mathrm{C} 1$ & $\begin{array}{llll}0.64266 & 0.65220 & -0.18974\end{array}$ & \# 1 \\
\hline N2 & $\begin{array}{lll}0.35517 & 0.66897 & -0.21570\end{array}$ & $\# 2$ \\
\hline N3 & $\begin{array}{llll}0.49962 & 0.57444 & -0.26510\end{array}$ & $\# 3$ \\
\hline $\mathrm{H}^{* 4}$ & $\begin{array}{llll}0.53431 & 0.58563 & -0.36823\end{array}$ & $\# 4$ \\
\hline H5 & $\begin{array}{lll}0.79961 & 0.70182 & -0.23448\end{array}$ & $\# 5$ \\
\hline $\mathrm{H}^{*} 6$ & $0.24530 \quad 0.64487 \quad-0.13112$ & $\# 6$ \\
\hline N'7 & $\begin{array}{llll}0.73433 & 0.61820 & -0.04811\end{array}$ & \# 7 \\
\hline $\mathrm{O} 8$ & $\begin{array}{llll}0.98337 & 0.62512 & -0.02487\end{array}$ & $\# 8$ \\
\hline O9 & $\begin{array}{lll}0.55666 & 0.58717 & 0.03150\end{array}$ & \# 9 \\
\hline$\# \mathrm{XC1}$ & $\begin{array}{llll}0.71893 & 0.64849 & -0.11133\end{array}$ & $\# 10$ \\
\hline \#XN2 & $\begin{array}{lll}0.32809 & 0.69442 & -0.25067\end{array}$ & \# 11 \\
\hline \#XN3 & $\begin{array}{llll}0.46871 & 0.53904 & -0.23835\end{array}$ & \# 12 \\
\hline$\# \mathrm{XH}^{* 4}$ & $\begin{array}{lll}0.53237 & 0.57793 & -0.39650\end{array}$ & \# 13 \\
\hline \#XH5 & $\begin{array}{lll}0.88531 & 0.72844 & -0.25561\end{array}$ & \# 14 \\
\hline$\# \mathrm{XH}^{*} 6$ & $\begin{array}{llll}0.24566 & 0.64931 & -0.14213\end{array}$ & \# 15 \\
\hline \#XN'7 & $\begin{array}{llll}0.70959 & 0.62334 & -0.06864\end{array}$ & \# 16 \\
\hline \#XO8 & $0.91043 \quad 0.61236 \quad 0.01182$ & \# 17 \\
\hline \#XO9 & $\begin{array}{lll}0.62960 & 0.58314 & 0.03202\end{array}$ & \# 18 \\
\hline$\#$ XLP2+ & $+\quad 0.36421 \quad 0.60110-0.22605$ & \# 19 \\
\hline \#XLP2- & $\begin{array}{lll}0.36604 & 0.64903 & -0.21510\end{array}$ & $\# 20$ \\
\hline \#XLP3+ & $\begin{array}{llll}0.48468 & 0.61684 & -0.26417\end{array}$ & \# 21 \\
\hline \#XLP3- & $\begin{array}{llll}0.46711 & 0.64856 & -0.25141\end{array}$ & $\# 22$ \\
\hline \#XLP7+ & $\begin{array}{lll}0.77326 & 0.56989 & -0.01240\end{array}$ & \# 23 \\
\hline \#XLP7- & $0.75108 \quad 0.65164 \quad 0.02931$ & \# 24 \\
\hline \#XLP8+ & $\begin{array}{llll}0.91603 & 0.60904 & -0.00496\end{array}$ & $\# 25$ \\
\hline \#XLP8- & $\begin{array}{llll}0.95866 & 0.64978 & -0.09819\end{array}$ & \# 26 \\
\hline \#XLP9+ & $\begin{array}{lll}0.63622 & 0.58204 & 0.03636\end{array}$ & \# 27 \\
\hline \#XLP9- & $\begin{array}{llll}0.51803 & 0.61456 & -0.00233\end{array}$ & \# 28 \\
\hline
\end{tabular}




\begin{tabular}{|c|c|c|}
\hline $\mathrm{C} 1$ & $\begin{array}{lll}-0.33909 & 0.15080 & 0.55303\end{array}$ & \# 29 \\
\hline $\mathrm{N} 2$ & $\begin{array}{lll}-0.62463 & 0.17261 & 0.52876\end{array}$ & \# 30 \\
\hline N3 & $\begin{array}{lll}-0.49522 & 0.07487 & 0.48069\end{array}$ & \# 31 \\
\hline $\mathrm{H}^{* 4}$ & $\begin{array}{lll}-0.46226 & 0.08405 & 0.37706\end{array}$ & \# 32 \\
\hline H5 & $\begin{array}{lll}-0.17681 & 0.19681 & 0.50591\end{array}$ & \# 33 \\
\hline $\mathrm{H}^{*} 6$ & $-0.73507 \quad 0.15171 \quad 0.61473$ & $\# 34$ \\
\hline $\mathrm{N}^{\prime} 7$ & $\begin{array}{lll}-0.24787 & 0.11696 & 0.69481\end{array}$ & \# 35 \\
\hline O8 & $\begin{array}{lll}0.00251 & 0.11949 & 0.71604\end{array}$ & $\# 36$ \\
\hline O9 & $\begin{array}{lll}-0.42713 & 0.09035 & 0.77648\end{array}$ & \# 37 \\
\hline$\# \mathrm{XC1}$ & $\begin{array}{lll}-0.26099 & 0.14668 & 0.63095\end{array}$ & $\# 38$ \\
\hline \#XN2 & $\begin{array}{lll}-0.64920 & 0.19809 & 0.49336\end{array}$ & \# 39 \\
\hline$\# \mathrm{XN} 3$ & $\begin{array}{lll}-0.53022 & 0.04045 & 0.50856\end{array}$ & $\# 40$ \\
\hline$\# \mathrm{XH} * 4$ & $\begin{array}{lll}-0.46616 & 0.07604 & 0.34901\end{array}$ & \# 41 \\
\hline \#XH5 & $\begin{array}{lll}-0.08816 & 0.22151 & 0.48348\end{array}$ & $\# 42$ \\
\hline$\# \mathrm{XH} * 6$ & $-0.73443 \quad 0.15600 \quad 0.60361$ & \# 43 \\
\hline$\# \mathrm{XN}$ '7 & $\begin{array}{lll}-0.27249 & 0.12230 & 0.67434\end{array}$ & $\# 44$ \\
\hline \#XO8 & $\begin{array}{lll}-0.07095 & 0.10860 & 0.75357\end{array}$ & $\# 45$ \\
\hline \#ХO9 & $\begin{array}{lll}-0.35484 & 0.08496 & 0.77656\end{array}$ & \# 46 \\
\hline \#XLP2+ & 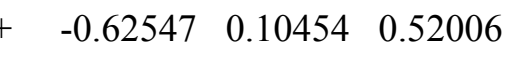 & \# 47 \\
\hline \#XLP2- & $\begin{array}{lll}-0.61656 & 0.15251 & 0.52978\end{array}$ & \# 48 \\
\hline \#XLP3+ & 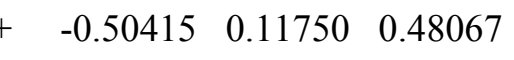 & $\# 49$ \\
\hline \#XLP3- & $\begin{array}{lll}-0.51685 & 0.14967 & 0.49276\end{array}$ & $\# 50$ \\
\hline \#XLP7+ & $+\quad-0.21465 \quad 0.06845 \quad 0.73144$ & $\# 51$ \\
\hline \#XLP7- & $\begin{array}{lll}-0.22401 & 0.15104 & 0.77125\end{array}$ & \# 52 \\
\hline \#XLP8+ & $+\quad-0.06635 \quad 0.10497 \quad 0.73685$ & $\# 53$ \\
\hline \#XLP8- & $\begin{array}{lll}-0.02100 & 0.14363 & 0.64230\end{array}$ & \# 54 \\
\hline \#XLP9+ & $+\quad-0.34825 \quad 0.08380 \quad 0.78089$ & $\# 55$ \\
\hline \#XLP9- & $\begin{array}{lll}-0.46292 & 0.11799 & 0.74225\end{array}$ & \# 56 \\
\hline
\end{tabular}

\section{1,2-dinitrodiaziridine (trans-form)}

data $-1.86803 \mathrm{E}+01$

_chemical_name_systematic

;RAS DNDAZ_2 PVDZ 
$\mathrm{E}($ total $)=-1.86803 \mathrm{E}+01 \mathrm{E}(\mathrm{coul})=-5.47662 \mathrm{E}+00 \mathrm{E}(\mathrm{vdW})=-1.32037 \mathrm{E}+01$ Density $=1.90198$

;

_cell_length_a 8.521

_cell_length_b 9.292

_cell_length_c 5.914

_cell_angle_alpha 90.00

_cell_angle_beta 90.00

_cell_angle_gamma 90.00

_cell_formula_units_Z 4

_symmetry_space_group_name_H-M 'P CA21 '

_symmetry_Int_Tables_number 29

loop_

_symmetry_equiv_pos_as_xyz

$1 \mathrm{x}, \mathrm{y}, \mathrm{z}$

$21 / 2-x, y, 1 / 2+z$

$31 / 2+x,-y, z$

$4-\mathrm{x},-\mathrm{y}, 1 / 2+\mathrm{z}$

loop_

_atom_site_label

_atom_site_fract_x

_atom_site_fract_y

_atom_site_fract_z

$\begin{array}{lllll}\text { C1 } & 0.63277 & -0.25000 & 0.30794 & \# 1\end{array}$

H2 $0.69924 \quad-0.35007 \quad 0.32180 \quad$ \#2

H3 $0.69924-0.149920 .29408 \quad$ \# 3

$\begin{array}{lllll}\mathrm{N} 4 & 0.48419 & -0.23614 & 0.42746 & \# 4\end{array}$

$\begin{array}{lllll}\text { N5 } & 0.48419 & -0.26386 & 0.18842\end{array}$

$\begin{array}{lllll}\text { N'6 } & 0.43356 & -0.13216 & 0.06320\end{array}$

$\begin{array}{lllll}\text { O7 } & 0.30448 & -0.08757 & 0.10800 & \# 7\end{array}$

O8 $0.52602-0.09220-0.07983 \quad \# 8$

$\begin{array}{lllll}\text { N'9 } & 0.43356 & -0.36784 & 0.55268\end{array}$ \# 9

$\begin{array}{lllll}\text { O10 } & 0.30448 & -0.41243 & 0.50788 & \text { \# } 10\end{array}$

$\begin{array}{lllll}\text { O11 } & 0.52602 & -0.40780 & 0.69571\end{array}$

$\begin{array}{lllll}\text { \#XC1 } & 0.57069 & -0.25000 & 0.30794\end{array}$

$\begin{array}{lllll}\text { \#XH2 } & 0.72508 & -0.40068 & 0.33507 & \# 13\end{array}$ 


\begin{tabular}{|c|c|c|c|}
\hline \#XH3 & $0.72507-0.09931$ & 0.28082 & \# 14 \\
\hline \#XN4 & $0.47950-0.21675$ & 0.43669 & \# 15 \\
\hline \#XN5 & $0.47950-0.28325$ & 0.17919 & \# 16 \\
\hline$\# X N^{\prime} 6$ & $0.43073-0.15838$ & 0.06985 & \# 17 \\
\hline \#XO7 & $0.34160-0.09562$ & 0.06982 & \# 18 \\
\hline \#XO8 & $0.52952-0.12083$ & 0.01908 & \# 19 \\
\hline \#XN'9 & $0.43073-0.34162$ & 0.54603 & $\# 20$ \\
\hline \#XO10 & $0.34160-0.40439$ & 0.54606 & \# 21 \\
\hline \#XO11 & $0.52952-0.37917$ & 0.59680 & \# 22 \\
\hline \#XLP4+ & $0.47124-0.22287$ & $7 \quad 0.42578$ & \#23 \\
\hline \#XLP4- & $0.44682-0.25894$ & 0.34043 & \# 24 \\
\hline \#XLP5+ & $0.47124-0.27713$ & 30.19010 & $\# 25$ \\
\hline \#XLP5- & $0.44682-0.24106$ & 0.27544 & \# 26 \\
\hline \#XLP6+ & $0.45920-0.12659$ & 0.07062 & \# 27 \\
\hline \#XLP6- & $0.41162-0.16731$ & 0.06137 & \# 28 \\
\hline \#XLP7+ & $0.46032-0.03835$ & 0.07726 & \# 29 \\
\hline \#XLP7- & $0.46465-0.09252$ & 0.10733 & \# 30 \\
\hline \#XLP8+ & $0.43515-0.08617$ & $7-0.09328$ & \#31 \\
\hline \#XLP8- & $0.40594-0.09633$ & -0.09506 & \# 32 \\
\hline \#XLP9+ & $\begin{array}{lll}0.45920 & -0.37341\end{array}$ & 0.54526 & \# 33 \\
\hline \#XLP9- & $0.41162-0.33269$ & 0.55451 & \#34 \\
\hline \#XL10+ & $0.46033-0.46165$ & 0.53862 & \# 35 \\
\hline \#XL10- & $0.46466-0.40748$ & 0.50855 & \# 36 \\
\hline \#XL11+ & $0.43515-0.41383$ & 0.70916 & \# 37 \\
\hline \#XL11- & $0.40594-0.40367$ & 0.71093 & \# 38 \\
\hline
\end{tabular}

\#END

\section{1,3-dinitrodiaziridine (trans-form)}

data $-2.19718 \mathrm{E}+01$

_chemical_name_systematic

;RAS DNDAZ_2i PVDZ

$E($ total $)=-2.19718 \mathrm{E}+01 \mathrm{E}(\mathrm{coul})=-9.23576 \mathrm{E}+00 \mathrm{E}(\mathrm{vdW})=-1.27360 \mathrm{E}+01$ Density $=1.88765$

;

_cell_length_a 8.903 
_cell_length_b 9.556

_cell_length_c 11.091

_cell_angle_alpha 90.00

_cell_angle_beta 90.00

_cell_angle_gamma 90.00

_cell_formula_units_Z 8

_symmetry_space_group_name_H-M 'P BCA '

_symmetry_Int_Tables_number 61

loop_

_symmetry_equiv_pos_as_xyz

$1 \mathrm{x}, \mathrm{y}, \mathrm{z}$

$21 / 2-x, 1 / 2+y, z$

$3 \mathrm{x}, 1 / 2-\mathrm{y}, 1 / 2+\mathrm{z}$

$41 / 2-x,-y, 1 / 2+z$

$5-\mathrm{x},-\mathrm{y},-\mathrm{z}$

6 1/2+x,1/2-y,-z

$7-\mathrm{x}, 1 / 2+\mathrm{y}, 1 / 2-\mathrm{z}$

$81 / 2+x, y, 1 / 2-z$

loop_

_atom_site_label

_atom_site_fract_x

_atom_site_fract_y

_atom_site_fract_z

$\begin{array}{lllll}\text { C1 } & 0.63115 & -0.28199 & -0.16792\end{array}$

$\begin{array}{llll}\mathrm{N} 2 & 0.57153 & -0.42029 & -0.18485\end{array}$

N3 $\quad 0.47161 \quad-0.30021 \quad-0.16683 \quad$ \# 3

$\begin{array}{lllll}\text { N'4 } & 0.57190 & -0.46348 & -0.31520 & \text { \# } 4\end{array}$

O5 $0.45066 \quad-0.49027-0.35759 \quad$ \# 5

O6 $0.69618-0.47588-0.35863 \quad$ \# 6

$\begin{array}{lllll}\text { N'7 } & 0.71529 & -0.26548 & -0.05071 & \text { \# } 7\end{array}$

$\begin{array}{lllll}\text { O8 } & 0.84375 & -0.22223 & -0.05940 & \# 8\end{array}$

$\begin{array}{lllll}\text { O9 } & 0.64810 & -0.29570 & 0.04185 & \text { \# } 9\end{array}$

$\begin{array}{lllll}\text { H10 } & 0.68539 & -0.22385 & -0.24032 & \# 10\end{array}$

$\begin{array}{lllll}\mathrm{H}^{*} 11 & 0.43333 & -0.31084 & -0.07999\end{array}$

$\begin{array}{lllll}\text { \#XC1 } & 0.59799 & -0.31833 & -0.17631 & \# 12\end{array}$ 


\begin{tabular}{|c|c|c|}
\hline \#XN2 & $0.56683-0.42522-0.13652$ & \# 13 \\
\hline \#XN3 & $0.45331-0.28939-0.19089$ & \# 14 \\
\hline \#XN'4 & $0.56813-0.48135-0.30567$ & \# 15 \\
\hline \#XO5 & $\begin{array}{llll}0.49867 & -0.48899 & -0.36434\end{array}$ & \# 16 \\
\hline \#XO6 & $\begin{array}{llll}0.67206 & -0.46186 & -0.35435\end{array}$ & \# 17 \\
\hline \#XN'7 & $\begin{array}{lll}0.69648 & -0.26487 & -0.04785\end{array}$ & \# 18 \\
\hline \#XO8 & $\begin{array}{llll}0.83866 & -0.23517 & -0.02819\end{array}$ & \# 19 \\
\hline \#XO9 & $\begin{array}{lll}0.68664 & -0.28652 & 0.02431\end{array}$ & \# 20 \\
\hline \#XH10 & $0.71215 \quad-0.19670 \quad-0.27214$ & \#21 \\
\hline$\# \mathrm{XH}^{*} 11$ & $\begin{array}{llll}0.41961 & -0.30572 & -0.08734\end{array}$ & $\# 22$ \\
\hline \#XLP2+ & $\begin{array}{lll}0.58785 & -0.36763 & -0.22020\end{array}$ & \# 23 \\
\hline \#XLP2- & $\begin{array}{lll}0.56960 & -0.39297 & -0.18319\end{array}$ & $\# 24$ \\
\hline \#XLP3+ & $\begin{array}{llll}0.48067 & -0.33192 & -0.15376\end{array}$ & \# 25 \\
\hline \#XLP3- & $0.46222-0.40575-0.13561$ & \#26 \\
\hline \#XLP4+ & $0.57502-0.41012-0.35352$ & \# 27 \\
\hline \#XLP4- & $\begin{array}{llll}0.57763 & -0.51568 & -0.32136\end{array}$ & \# 28 \\
\hline \#XLP5+ & $\begin{array}{llll}0.49426 & -0.49448 & -0.36562\end{array}$ & $\# 29$ \\
\hline \#XLP5- & $\begin{array}{llll}0.43953 & -0.48120 & -0.29777\end{array}$ & \# 30 \\
\hline \#XLP6+ & $\begin{array}{llll}0.71803 & -0.44989 & -0.37562\end{array}$ & \# 31 \\
\hline \#XLP6- & $\begin{array}{llll}0.67088 & -0.46562 & -0.35850\end{array}$ & \# 32 \\
\hline \#XLP7+ & $0.69936-0.22752-0.03658$ & \# 33 \\
\hline \#XLP7- & $\begin{array}{lll}0.75389 & -0.28906 & -0.02940\end{array}$ & \# 34 \\
\hline \#XLP8+ & $\begin{array}{llll}0.82540 & -0.23650 & -0.09894\end{array}$ & \#35 \\
\hline \#XLP8- & $\begin{array}{lll}0.87193 & -0.23023 & -0.07018\end{array}$ & \#36 \\
\hline \#XLP9+ & $\begin{array}{lll}0.70783 & -0.19377 & 0.02150\end{array}$ & \# 37 \\
\hline \#XLP9- & $\begin{array}{lll}0.67120 & -0.25879 & 0.01146\end{array}$ & \# 38 \\
\hline
\end{tabular}

\section{3,3-dinitrodiaziridine (trans-form)}

data $-2.31621 \mathrm{E}+01$

_chemical_name_systematic

;RAS DNDAZ_2ii PVDZ

$\mathrm{E}($ total $)=-2.31621 \mathrm{E}+01 \mathrm{E}(\mathrm{coul})=-8.65957 \mathrm{E}+00 \mathrm{E}(\mathrm{vdW})=-1.45025 \mathrm{E}+01$ Density $=1.95840$ 
_cell_length_a 7.351

_cell_length_b 8.636

_cell_length_c 7.183

_cell_angle_alpha 90.00

_cell_angle_beta 94.38

_cell_angle_gamma 90.00

_cell_formula_units_Z 4

_symmetry_space_group_name_H-M 'P 21/N '

_symmetry_Int_Tables_number 14

loop_

_symmetry_equiv_pos_as_xyz

$1 \mathrm{x}, \mathrm{y}, \mathrm{z}$

$21 / 2-x, 1 / 2+y, 1 / 2-z$

$3-\mathrm{x},-\mathrm{y},-\mathrm{z}$

$41 / 2+x, 1 / 2-y, 1 / 2+z$

loop_

_atom_site_label

_atom_site_fract_x

_atom_site_fract_y

_atom_site_fract_z

$\begin{array}{llll}\text { C1 } & 0.50000 & -0.21873 & 0.24998\end{array}$

\# 1

$\begin{array}{llll}\mathrm{N} 2 & 0.50801 & -0.35588 & 0.35633\end{array}$

\# 2

N3 $\quad \begin{array}{llll}0.49195 & -0.35585 & 0.14357\end{array}$

\# 3

$\begin{array}{llll}\text { N'4 } & 0.67017 & -0.11925 & 0.27304\end{array}$

\# 4

$\begin{array}{llll}\text { O5 } & 0.79875 & -0.16131 & 0.18784\end{array}$

\# 5

$\begin{array}{llll}\text { O6 } & 0.66396 & -0.01030 & 0.37968\end{array}$

\# 6

$\begin{array}{llll}H^{* 7} & 0.62058 & -0.38043 & 0.10559\end{array}$

\# 7

$\begin{array}{llll}\text { N'8 } & 0.32988 & -0.11920 & 0.22696\end{array}$

\# 8

$\begin{array}{llll}\text { O9 } & 0.20128 & -0.16125 & 0.31214\end{array}$

\# 9

$\begin{array}{llll}\text { O10 } & 0.33613 & -0.01022 & 0.12036\end{array}$

\# 10

$\begin{array}{llll}\mathrm{H}^{*} 11 & 0.37936 & -0.38044 & 0.39431\end{array}$

\# 11

$\begin{array}{llll}\text { \#XC1 } & 0.50001 & -0.17330 & 0.24999\end{array}$

\# 12

$\begin{array}{llll}\text { \#XN2 } & 0.57267 & -0.38924 & 0.41132\end{array}$

\# 13

$\begin{array}{llll}\text { \#XN3 } & 0.42727 & -0.38918 & 0.08857\end{array}$

\# 14

$\begin{array}{llll}\text { \#XN'4 } & 0.68281 & -0.09343 & 0.27387\end{array}$

\# 15 


\begin{tabular}{|c|c|c|c|}
\hline \#XO5 & $0.77017-0.13836$ & 0.20336 & \# 16 \\
\hline \#XO6 & $0.73044-0.00213$ & 0.36004 & \# 17 \\
\hline$\# \mathrm{XH} * 7$ & $0.62265-0.38212$ & 0.10423 & \# 18 \\
\hline \#XN'8 & $0.31724-0.09338$ & 0.22614 & \# 19 \\
\hline \#XO9 & $0.22987-0.13830$ & 0.29664 & \# 20 \\
\hline \#XO10 & $0.26966-0.00204$ & 0.14001 & \# 21 \\
\hline$\# \mathrm{XH}^{*} 11$ & $0.37730-0.38212$ & 0.39567 & \# 22 \\
\hline \#XLP2+ & $0.48762-0.15292$ & 0.37080 & \# 23 \\
\hline \#XLP2- & $0.56392-0.10275$ & 0.35268 & $\# 24$ \\
\hline \#XLP3+ & $0.51241-0.15290$ & 0.12919 & \# 25 \\
\hline \#XLP3- & $0.43613-0.10270$ & 0.14733 & \#26 \\
\hline \#XLP4+ & $0.67898-0.18741$ & 0.26331 & \# 27 \\
\hline \#XLP4- & $0.66784-0.13459$ & 0.29300 & \# 28 \\
\hline \#XLP5+ & $0.70364-0.19967$ & 0.16143 & \# 29 \\
\hline \#XLP5- & $0.83050-0.11810$ & 0.22194 & \# 30 \\
\hline \#XLP6+ & $0.64461-0.18312$ & 0.36984 & \# 31 \\
\hline \#XLP6- & $0.71106-0.15760$ & 0.39029 & \# 32 \\
\hline \#XLP8+ & $0.32105-0.18736$ & 0.23667 & \# 33 \\
\hline \#XLP8- & $0.33220-0.13453$ & 0.20700 & \#34 \\
\hline \#XLP9+ & $0.29638-0.19964$ & 0.33854 & \# 35 \\
\hline \#XLP9- & $0.16955-0.11803$ & 0.27807 & \#36 \\
\hline \#XL10+ & $0.35541-0.18305$ & 0.13014 & \# 37 \\
\hline \#XL10- & $0.28897-0.15751$ & 0.10969 & \# 38 \\
\hline
\end{tabular}

\section{1,2,3-trinitrodiaziridine (trans-form)}

data $-4.10334 \mathrm{E}+01$

_chemical_name_systematic

;RAS DNDAZ_3 PVDZ

$\mathrm{E}($ total $)=-4.10334 \mathrm{E}+01 \mathrm{E}(\mathrm{coul})=-1.04619 \mathrm{E}+01 \mathrm{E}(\mathrm{vdW})=-3.05715 \mathrm{E}+01$ Density $=1.98916$

;

_cell_length_a 10.335

_cell_length_b 10.287

_cell_length_c 11.391 
_cell_angle_alpha 90.00

_cell_angle_beta 99.07

_cell_angle_gamma 90.00

_cell_formula_units_Z 4

_symmetry_space_group_name_H-M 'P 21/A '

_symmetry_Int_Tables_number 14

loop_

_symmetry_equiv_pos_as_xyz

$1 \mathrm{x}, \mathrm{y}, \mathrm{z}$

$21 / 2-\mathrm{x}, 1 / 2+\mathrm{y},-\mathrm{z}$

$3-\mathrm{x},-\mathrm{y},-\mathrm{z}$

$41 / 2+x, 1 / 2-y, z$

loop_

_atom_site_label

_atom_site_fract_x

_atom_site_fract_y

_atom_site_fract_z

$\begin{array}{lllll}\text { C1 } & 0.24744 & 0.32049 & -0.41178\end{array}$

N2 $0.26135 \quad 0.45927 \quad-0.41783 \quad$ \#2

N3 $0.28451 \quad 0.38154-0.51582 \quad$ \# 3

$\begin{array}{lllll} & \text { N'4 } & 0.17719 & 0.40050 & -0.62449\end{array}$

O5 $0.14951 \quad 0.51108-0.64991 \quad$ \# 5

O6 $0.14483 \quad 0.29949-0.67417 \quad$ \# 6

$\begin{array}{lllll}\text { N'7 } & 0.38968 & 0.51096 & -0.34990 & \# 7\end{array}$

O8 $\quad 0.45600 \quad 0.57101 \quad-0.40853 \quad$ \#

O9 $0.40303 \quad 0.49060-0.24419 \quad$ \# 9

$\begin{array}{lllll}\mathrm{N}^{\prime} 10 & 0.10901 & 0.27475 & -0.40847\end{array}$ \# 10

$\begin{array}{llllll}\text { O11 } & 0.10142 & 0.17366 & -0.35386\end{array}$

$\begin{array}{llllll}\text { O12 } & 0.01970 & 0.34100 & -0.45914\end{array}$

$\begin{array}{llllll}\mathrm{H} 13 & 0.31858 & 0.25704 & -0.35900 \quad \text { \# } 13\end{array}$

$\begin{array}{lllll}\text { \#XC1 } & 0.21607 & 0.30417 & -0.39594\end{array}$

$\begin{array}{lllll}\text { \#XN2 } & 0.23218 & 0.44524 & -0.41841\end{array}$

$\begin{array}{lllll}\text { \#XN3 } & 0.32373 & 0.39765 & -0.51105 & \text { \# } 16\end{array}$

$\begin{array}{lllll}\text { \#XN'4 } & 0.18800 & 0.40226 & -0.62193\end{array}$

$\begin{array}{llllll}\text { \#XO5 } & 0.10896 & 0.49251 & -0.69066\end{array}$ 


\begin{tabular}{|c|c|c|c|}
\hline \#XO6 & 0.19330 & $0.30326-0.63283$ & \# 19 \\
\hline \#XN'7 & 0.38017 & $0.50238-0.36363$ & \# 20 \\
\hline \#XO8 & 0.47426 & $0.58401 \quad-0.35832$ & \#21 \\
\hline \#XO9 & 0.43407 & $0.49526-0.23056$ & \# 22 \\
\hline \#XN'10 & 0.12073 & $0.26672-0.42430$ & \#23 \\
\hline \#XO11 & 0.07409 & $0.22230-0.38553$ & \# 24 \\
\hline \#XO12 & 0.01770 & $0.28861-0.43527$ & \# 25 \\
\hline \#XH13 & 0.33280 & $0.23693-0.33489$ & \#26 \\
\hline \#XLP2+ & 0.24352 & $\begin{array}{llll}2 & 0.44335 & -0.41637\end{array}$ & \# 27 \\
\hline \#XLP2- & 0.29527 & $0.41627-0.42034$ & \# 28 \\
\hline \#XLP3+ & 0.19549 & $\begin{array}{llll}9 & 0.41687 & -0.47300\end{array}$ & \# 29 \\
\hline \#XLP3- & 0.27106 & $0.40831-0.50142$ & \# 30 \\
\hline \#XLP4+ & 0.15794 & $\begin{array}{lll}4 & 0.40961 & -0.63878\end{array}$ & \# 31 \\
\hline \#XLP4- & 0.21103 & $0.39813-0.61266$ & \# 32 \\
\hline \#XLP5+ & 0.17776 & $\begin{array}{llll}6 & 0.48697 & -0.64341\end{array}$ & \# 33 \\
\hline \#XLP5- & 0.21750 & $0.41971-0.61831$ & \# 34 \\
\hline \#XLP6+ & 0.06985 & $\begin{array}{lll}5 & 0.39439 & -0.61135\end{array}$ & \# 35 \\
\hline \#XLP6- & 0.11551 & $0.33313-0.70258$ & \#36 \\
\hline \#XLP7+ & 0.41894 & $4 \quad 0.52755-0.34756$ & \# 37 \\
\hline \#XLP7- & 0.41085 & $0.47948-0.33858$ & \# 38 \\
\hline \#XLP8+ & 0.38600 & $\begin{array}{llll}0 & 0.57349 & -0.45241\end{array}$ & \# 39 \\
\hline \#XLP8- & 0.46619 & $0.51549-0.38309$ & \# 40 \\
\hline \#XLP9+ & 0.36423 & $\begin{array}{llll}3 & 0.44368 & -0.27273\end{array}$ & \# 41 \\
\hline \#XLP9- & 0.42543 & $0.47158-0.20420$ & \# 42 \\
\hline \#XL10+ & 0.11035 & $5 \quad 0.27211 \quad-0.37911$ & \# 43 \\
\hline \#XL10- & 0.18480 & $0.21612-0.35398$ & \# 44 \\
\hline \#XL11+ & 0.03254 & $\begin{array}{lll}4 & 0.26847 & -0.38696\end{array}$ & \# 45 \\
\hline \#XL11- & 0.03595 & $0.19780-0.38006$ & \# 46 \\
\hline \#XL12+ & 0.07258 & $8 \quad 0.29675 \quad-0.46901$ & $\# 47$ \\
\hline \#XL12- & 0.03364 & $0.23924-0.42368$ & \# 48 \\
\hline $\mathrm{C} 1$ & $0.07067 \quad 0$. & $.74151-0.02611$ & \# 49 \\
\hline $\mathrm{N} 2$ & 0.168750. & $.71713-0.09994$ & \# 50 \\
\hline N3 & $0.09680 \quad 0$. & $.83563-0.11361$ & \# 51 \\
\hline N'4 & $0.18321 \quad 0$. & $.95313-0.06974$ & \# 52 \\
\hline O5 & $0.28678 \quad 0$. & $.95797-0.10409$ & \# 53 \\
\hline
\end{tabular}




\begin{tabular}{|c|c|c|}
\hline O6 & $\begin{array}{lll}0.12757 & 1.02935 & -0.01468\end{array}$ & $\# 54$ \\
\hline N'7 & $\begin{array}{llll}0.12439 & 0.62599 & -0.20377\end{array}$ & \# 55 \\
\hline $\mathrm{O} 8$ & $\begin{array}{llll}0.12974 & 0.67054 & -0.30031\end{array}$ & \# 56 \\
\hline O9 & $\begin{array}{lll}0.09722 & 0.51805 & -0.17355\end{array}$ & \# 57 \\
\hline N'10 & $\begin{array}{lll}0.12410 & 0.75692 & 0.10456\end{array}$ & $\# 58$ \\
\hline $\mathrm{O} 11$ & $\begin{array}{lll}0.04963 & 0.72159 & 0.17145\end{array}$ & \# 59 \\
\hline $\mathrm{O} 12$ & $\begin{array}{lll}0.23376 & 0.80194 & 0.13087\end{array}$ & \# 60 \\
\hline H13 & $\begin{array}{lll}-0.02524 & 0.69485 & -0.03863\end{array}$ & \#61 \\
\hline$\# \mathrm{XC1}$ & $\begin{array}{lll}0.07778 & 0.73037 & 0.01067\end{array}$ & \#62 \\
\hline \#XN2 & $\begin{array}{llll}0.17667 & 0.72267 & -0.07086\end{array}$ & \#63 \\
\hline \#XN3 & $\begin{array}{lll}0.08392 & 0.82457 & -0.15030\end{array}$ & \# 64 \\
\hline \#XN'4 & $\begin{array}{llll}0.17756 & 0.94936 & -0.07830\end{array}$ & \# 65 \\
\hline \#XO5 & $\begin{array}{lll}0.29961 & 1.00758 & -0.07610\end{array}$ & \#66 \\
\hline \#XO6 & $\begin{array}{llll}0.09825 & 0.98179 & -0.04226\end{array}$ & \#67 \\
\hline \#XN'7 & $\begin{array}{lll}0.12426 & 0.64294 & -0.19660\end{array}$ & \# 68 \\
\hline \#ХO8 & $\begin{array}{lll}0.12664 & 0.61362 & -0.30536\end{array}$ & \# 69 \\
\hline \#XO9 & $\begin{array}{lll}0.08054 & 0.50065 & -0.19606\end{array}$ & \# 70 \\
\hline \#XN'10 & $\begin{array}{lll}0.11085 & 0.77456 & 0.09405\end{array}$ & \# 71 \\
\hline \#XO11 & $0.10548 \quad 0.74630 \quad 0.16216$ & \# 72 \\
\hline \#XO12 & $\begin{array}{lll}0.19405 & 0.78817 & 0.16267\end{array}$ & \# 73 \\
\hline \#ХH13 & $\begin{array}{lll}-0.05051 & 0.67283 & -0.03379\end{array}$ & \# 74 \\
\hline \#XLP2+ & $\begin{array}{llll}0.16789 & 0.72018 & -0.07839\end{array}$ & \# 75 \\
\hline \#XLP2- & $\begin{array}{lll}0.11398 & 0.72680 & -0.10864\end{array}$ & \# 76 \\
\hline \#XLP3+ & $\begin{array}{lll}0.17986 & 0.78871 & -0.04579\end{array}$ & \# 77 \\
\hline \#XLP3- & $\begin{array}{llll}0.12562 & 0.81557 & -0.11040\end{array}$ & \# 78 \\
\hline \#XLP4+ & $\begin{array}{llll}0.20296 & 0.96750 & -0.06281\end{array}$ & \# 79 \\
\hline \#XLP4- & $\begin{array}{llll}0.15936 & 0.93896 & -0.09191\end{array}$ & \# 80 \\
\hline \#XLP5+ & $\begin{array}{lll}0.24992 & 0.95445 & -0.11390\end{array}$ & \# 81 \\
\hline \#XLP5- & $\begin{array}{lll}0.17198 & 0.93985 & -0.10823\end{array}$ & \# 82 \\
\hline \#XLP6+ & $\begin{array}{lll}0.24695 & 0.94763 & 0.02186\end{array}$ & \# 83 \\
\hline \#XLP6- & $\begin{array}{lll}0.17305 & 1.05399 & -0.01483\end{array}$ & \# 84 \\
\hline \#XLP7+ & $\begin{array}{llll}0.11835 & 0.61804 & -0.23351\end{array}$ & \# 85 \\
\hline \#XLP7- & $\begin{array}{lll}0.08628 & 0.61945 & -0.20328\end{array}$ & \# 86 \\
\hline \#XLP8+ & $\begin{array}{llll}0.17773 & 0.72085 & -0.25922\end{array}$ & \# 87 \\
\hline \#XLP8- & $\begin{array}{llll}0.07975 & 0.65499 & -0.27632\end{array}$ & \# 88 \\
\hline
\end{tabular}




$\begin{array}{lccccc}\text { \#XLP9+ } & 0.08677 & 0.56077 & -0.13081 & \text { \# } 89 \\ \text { \#XLP9- } & 0.06711 & 0.47852 & -0.17088 & \# 90 \\ \text { \#XL10+ } & 0.12040 & 0.72644 & 0.11351 & \# 91 \\ \text { \#XL10- } & 0.02888 & 0.70712 & 0.08676 & \# 92 \\ \text { \#XL11+ } & 0.16769 & 0.74060 & 0.17432 & \# 93 \\ \text { \#XL11- } & 0.11092 & 0.74830 & 0.20477 & \# 94 \\ \text { \#XL12+ } & 0.16608 & 0.81840 & 0.10549 & \# 95 \\ \text { \#XL12- } & 0.14550 & 0.78553 & 0.17524 & \# 96 \\ \text { \#END } & & & & \end{array}$

\section{1,3,3-trinitrodiaziridine (trans-form)}

data $\quad-2.33765 \mathrm{E}+01$

_chemical_name_systematic

;RAS DNDAZ_3i PVDZ

$\mathrm{E}($ total $)=-2.33765 \mathrm{E}+01 \mathrm{E}($ coul $)=-5.77151 \mathrm{E}+00 \mathrm{E}(\mathrm{vdW})=-1.76050 \mathrm{E}+01$ Density $=2.05164$

;

_cell_length_a 9.733

_cell_length_b 9.954

_cell_length_c 5.984

_cell_angle_alpha 90.00

_cell_angle_beta 90.00

_cell_angle_gamma 90.00

_cell_formula_units_Z 4

_symmetry_space_group_name_H-M 'P NA21 '

_symmetry_Int_Tables_number 33

loop_

_symmetry_equiv_pos_as_xyz

$1 \mathrm{x}, \mathrm{y}, \mathrm{z}$

$21 / 2-x, 1 / 2+y, 1 / 2+z$

$31 / 2+x, 1 / 2-y, z$

$4-\mathrm{x},-\mathrm{y}, 1 / 2+\mathrm{z}$

loop

_atom_site_label

_atom_site_fract_x 
_atom_site_fract_y

_atom_site_fract_z

$\begin{array}{llll}\text { C1 } & 0.22542 & 0.38829 & 0.47431\end{array}$

\# 1

$\begin{array}{lllll}\mathrm{N} 2 & 0.28196 & 0.44447 & 0.67331\end{array}$

\# 2

$\begin{array}{llll}\mathrm{N} 3 & 0.17829 & 0.33709 & 0.67927\end{array}$

\# 3

$\begin{array}{llll}\text { N'4 } & 0.42686 & 0.39150 & 0.74293\end{array}$

\# 4

$\begin{array}{lllll}\text { O5 } & 0.42865 & 0.29514 & 0.86289\end{array}$

\# 5

$\begin{array}{lllll}\text { O6 } & 0.51639 & 0.46457 & 0.67760\end{array}$

\# 6

$\begin{array}{llll}\text { N'7 } & 0.14246 & 0.48951 & 0.33887\end{array}$

\# 7

O8 $\quad 0.03082 \quad 0.51960 \quad 0.41661$

\# 8

$\begin{array}{lllll}\text { O9 } & 0.19773 & 0.53297 & 0.17194\end{array}$

\# 9

$\begin{array}{llll}\mathrm{H}^{*} 10 & 0.08714 & 0.38061 & 0.72633\end{array}$

\# 10

$\begin{array}{llll}\text { N'11 } & 0.29266 & 0.28682 & 0.31970\end{array}$

\# 11

$\begin{array}{llll}012 & 0.21428 & 0.23799 & 0.18361\end{array}$

\# 12

$\begin{array}{llll}013 & 0.41324 & 0.26128 & 0.34987\end{array}$

\# 13

$\begin{array}{llll}\text { \#XC1 } & 0.21498 & 0.36451 & 0.42837\end{array}$

\# 14

$\begin{array}{lllll}\text { \#XN2 } & 0.30469 & 0.44596 & 0.64278\end{array}$

\# 15

$\begin{array}{lllll}\text { \#XN3 } & 0.20408 & 0.29817 & 0.70951\end{array}$

\# 16

$\begin{array}{llll}\text { \#XN'4 } & 0.44216 & 0.39614 & 0.76723\end{array}$

\# 17

$\begin{array}{llll}\text { \#XO5 } & 0.42216 & 0.35538 & 0.81881\end{array}$

\# 18

$\begin{array}{llll}\text { \#XO6 } & 0.46527 & 0.42726 & 0.71436\end{array}$

\# 19

$\begin{array}{llll}\text { \#XN'7 } & 0.14599 & 0.55936 & 0.30480\end{array}$

\# 20

$\begin{array}{llll}\text { \#XO8 } & 0.07100 & 0.51930 & 0.35183\end{array}$

\# 21

$\begin{array}{llll}\text { \#XO9 } & 0.16251 & 0.53945 & 0.23501\end{array}$

\# 22

$\begin{array}{llll}\text { \#XH*10 } & 0.09213 & 0.37916 & 0.74082\end{array}$

\#23

$\begin{array}{llll}\text { \#XN'11 } & 0.28213 & 0.25649 & 0.33973\end{array}$

\# 24

$\begin{array}{llll}\text { \#XO12 } & 0.20173 & 0.25630 & 0.30078\end{array}$

\# 25

$\begin{array}{llll}\text { \#XO13 } & 0.41684 & 0.23839 & 0.26251\end{array}$

\# 26

$\begin{array}{llll}\text { \#XLP2+ } & 0.25402 & 0.49090 & 0.71016\end{array}$

\# 27

$\begin{array}{llll}\text { \#XLP2- } & 0.28063 & 0.42963 & 0.72825\end{array}$

\# 28

$\begin{array}{lllll}\text { \#XLP3+ } & 0.25748 & 0.48047 & 0.57982\end{array}$

\# 29

$\begin{array}{llll}\text { \#XLP3- } & 0.27633 & 0.42268 & 0.60438\end{array}$

\# 30

$\begin{array}{llll}\text { \#XLP4+ } & 0.44740 & 0.39028 & 0.76135\end{array}$

\# 31

$\begin{array}{llll}\text { \#XLP4- } & 0.39512 & 0.39328 & 0.76895\end{array}$

\# 32

$\begin{array}{llll}\text { \#XLP5+ } & 0.54253 & 0.41932 & 0.75828\end{array}$

\# 33 


$\begin{array}{lcccc}\text { \#XLP5- } & 0.47690 & 0.31877 & 0.83842 & \# 34 \\ \text { \#XLP6+ } & 0.45432 & 0.38837 & 0.76220 & \# 35 \\ \text { \#XLP6- } & 0.41909 & 0.35910 & 0.78029 & \# 36 \\ \text { \#XLP7+ } & 0.13366 & 0.47723 & 0.38898 & \# 37 \\ \text { \#XLP7- } & 0.11424 & 0.47115 & 0.36411 & \# 38 \\ \text { \#XLP8+ } & 0.07151 & 0.46942 & 0.44984 & \# 39 \\ \text { \#XLP8- } & 0.06699 & 0.52544 & 0.34804 & \# 40 \\ \text { \#XLP9+ } & 0.08767 & 0.47318 & 0.24740 & \# 41 \\ \text { \#XLP9- } & 0.10930 & 0.39816 & 0.24243 & \# 42 \\ \text { \#XL11+ } & 0.29393 & 0.30460 & 0.31417 & \# 43 \\ \text { \#XL11- } & 0.29625 & 0.25777 & 0.32262 & \# 44 \\ \text { \#XL12+ } & 0.34346 & 0.26830 & 0.18447 & \# 45 \\ \text { \#XL12- } & 0.27260 & 0.21391 & 0.16363 & \# 46 \\ \text { \#XL13+ } & 0.41656 & 0.23803 & 0.26655 & \# 47 \\ \text { \#XL13- } & 0.37506 & 0.21501 & 0.38320 & \# 48 \\ \text { \#END } & & & & \end{array}$

\section{1,2,3,3-tetranitrodiaziridine (trans-form)}

data $-2.15039 \mathrm{E}+01$

_chemical_name_systematic

;RAS DNDAZ_4 PVDZ

$\mathrm{E}($ total $)=-2.15039 \mathrm{E}+01 \mathrm{E}($ coul $)=-2.15938 \mathrm{E}+00 \mathrm{E}(\mathrm{vdW})=-1.93445 \mathrm{E}+01$ Density $=2.06490$

;

_cell_length_a 6.232

_cell_length_b 16.156

_cell_length_c 11.054

_cell_angle_alpha 90.00

_cell_angle_beta 139.64

_cell_angle_gamma 90.00

_cell_formula_units_Z 4

_symmetry_space_group_name_H-M 'P 21/C '

_symmetry_Int_Tables_number 14

loop_

_symmetry_equiv_pos_as_xyz 


\begin{tabular}{|c|c|c|c|}
\hline \multicolumn{4}{|l|}{$1 \mathrm{x}, \mathrm{y}, \mathrm{z}$} \\
\hline \multicolumn{4}{|c|}{$2-x, 1 / 2+y, 1 / 2-z$} \\
\hline \multicolumn{4}{|c|}{$3-x,-y,-z$} \\
\hline \multicolumn{4}{|c|}{$4 \mathrm{x}, 1 / 2-\mathrm{y}, 1 / 2+\mathrm{z}$} \\
\hline \multicolumn{4}{|c|}{ loop_ } \\
\hline \multicolumn{4}{|c|}{ _atom_site_label } \\
\hline \multicolumn{4}{|c|}{ atom_site_fract_x } \\
\hline \multicolumn{4}{|c|}{ atom_site_fract_y } \\
\hline \multicolumn{4}{|c|}{ atom_site_fract_z } \\
\hline $\mathrm{C} 1$ & $\begin{array}{ll}-0.93001 & 0 .\end{array}$ & $0.64676 \quad 0.14226$ & $\# 1$ \\
\hline N2 & $\begin{array}{ll}-0.92648 & 0\end{array}$ & $0.59765 \quad 0.03657$ & $\# 2$ \\
\hline N3 & $\begin{array}{ll}-0.62257 & 0\end{array}$ & $0.62747 \quad 0.21729$ & $\# 3$ \\
\hline N'4 & -0.420150 & $0.55479 \quad 0.36159$ & $\# 4$ \\
\hline O5 & -0.385300 & $0.49621 \quad 0.31179$ & $\# 5$ \\
\hline O6 & -0.311520 & $0.57166 \quad 0.50650$ & \# 6 \\
\hline N'7 & -1.009260. & $0.64401-0.11952$ & $\# 7$ \\
\hline $\mathrm{O} 8$ & $\begin{array}{ll}-0.78660 & 0\end{array}$ & $\begin{array}{lll}0.64596 & -0.09509\end{array}$ & \# 8 \\
\hline O9 & -1.293750. & $0.66582-0.24709$ & \# 9 \\
\hline N'10 & $\begin{array}{ll}-1.04643 & 0\end{array}$ & $0.73682 \quad 0.08818$ & \# 10 \\
\hline O11 & $-0.86018 \quad 0$ & $0.78574 \quad 0.11982$ & \# 11 \\
\hline $\mathrm{O} 12$ & -1.322200 & $0.74844 \quad 0.01016$ & \# 12 \\
\hline N'13 & -1.029640 & $0.60421 \quad 0.21762$ & \# 13 \\
\hline O14 & $\begin{array}{ll}-1.00048 \quad 0 & 0\end{array}$ & $\begin{array}{ll}0.64684 & 0.31995\end{array}$ & \# 14 \\
\hline O15 & $\begin{array}{ll}-1.109630 & 0\end{array}$ & $0.53193 \quad 0.17551$ & \# 15 \\
\hline \#XC1 & -0.92408 & $0.64545 \quad 0.14167$ & \# 16 \\
\hline \#XN2 & -0.97097 & $0.61416 \quad 0.03954$ & \# 17 \\
\hline \#XN3 & -0.67641 & $0.63259 \quad 0.22402$ & \# 18 \\
\hline \#XN'4 & -0.31041 & $0.54006 \quad 0.35026$ & \# 19 \\
\hline \#XO5 & -0.46073 & $0.53205 \quad 0.27268$ & \# 20 \\
\hline \#ХO6 & -0.30508 & $0.63035 \quad 0.50294$ & \# 21 \\
\hline \#XN'7 & -0.91559 & $0.61400-0.12822$ & \# 22 \\
\hline \#ХO8 & -0.80176 & $0.63004-0.04705$ & \# 23 \\
\hline \#XO9 & -1.39089 & $0.62708-0.23460$ & \# 24 \\
\hline$\#$ XN'10 & -1.12967 & $7 \quad 0.78729 \quad 0.04590$ & $\# 25$ \\
\hline \#XO11 & -1.03724 & $\begin{array}{lll}4 & 0.80443 & 0.06387\end{array}$ & \# 26 \\
\hline
\end{tabular}




\begin{tabular}{|c|c|c|c|c|}
\hline \#XO12 & -1.40283 & 0.75161 & -0.01246 & \# 27 \\
\hline \#XN'13 & -1.06805 & 0.58050 & 0.27189 & \# 28 \\
\hline \#XO14 & -0.99194 & 0.65952 & 0.34967 & \# 29 \\
\hline \#XO15 & -1.09939 & 0.54993 & 0.24790 & \# 30 \\
\hline \#XLP1+ & -0.87283 & 0.66569 & 0.17648 & \# 31 \\
\hline \#XLP1- & -1.01193 & 0.63327 & 0.11047 & \# 32 \\
\hline \#XLP2+ & -0.78776 & 0.72592 & 0.16670 & \# 33 \\
\hline \#XLP2- & -0.96400 & 0.58044 & 0.04451 & \# 34 \\
\hline \#XLP3+ & -0.62236 & 0.65289 & 0.21303 & \# 35 \\
\hline \#XLP3- & -1.06788 & 0.56663 & 0.11738 & \# 36 \\
\hline \#XLP4+ & -0.42810 & 0.58477 & 0.38391 & \# 37 \\
\hline \#XLP4- & -0.72447 & 0.52867 & 0.25886 & \# 38 \\
\hline \#XLP5+ & -0.22199 & 0.52293 & 0.36375 & \# 39 \\
\hline \#XLP5- & -0.26810 & 0.48320 & 0.43630 & \# 40 \\
\hline \#XLP6+ & -0.26249 & 0.52817 & 0.50632 & \# 41 \\
\hline \#XLP6- & -0.27892 & 0.50317 & 0.46005 & \# 42 \\
\hline \#XLP7+ & -0.87203 & 0.70689 & -0.00032 & $\# 43$ \\
\hline \#XLP7- & -1.11279 & 0.63855 & -0.13085 & \# 44 \\
\hline \#XLP8+ & -0.97143 & 0.67384 & -0.21294 & \# 45 \\
\hline \#XLP8- & -0.87691 & 0.60317 & -0.15425 & \# 46 \\
\hline \#XLP9+ & -1.06079 & 0.67590 & -0.22681 & $\# 47$ \\
\hline \#XLP9- & -1.19464 & 0.67673 & -0.26152 & \# 48 \\
\hline \#XL10+ & -1.13390 & 0.74183 & 0.07485 & $\# 49$ \\
\hline \#XL10- & -1.12669 & 0.70991 & 0.04545 & $\# 50$ \\
\hline \#XL11+ & -1.16864 & 0.73406 & 0.05225 & \# 51 \\
\hline \#XL11- & -1.23337 & 0.67466 & -0.03204 & \# 52 \\
\hline \#XL12+ & -1.28446 & 0.77646 & 0.01134 & \# 53 \\
\hline \#XL12- & -1.34486 & 0.72172 & 0.02113 & \# 54 \\
\hline \#XL13+ & -0.92489 & 0.62574 & 0.25794 & $\# 55$ \\
\hline \#XL13- & -1.04617 & 0.62208 & 0.24121 & \# 56 \\
\hline \#XL14+ & -0.98325 & 0.67476 & 0.30951 & $\# 57$ \\
\hline \#XL14- & -1.03898 & 0.61899 & 0.31884 & \# 58 \\
\hline \#XL15+ & -0.74426 & 0.64472 & 0.32814 & $\# 59$ \\
\hline \#XL15- & -0.99952 & 0.62723 & 0.26263 & \# 60 \\
\hline
\end{tabular}

